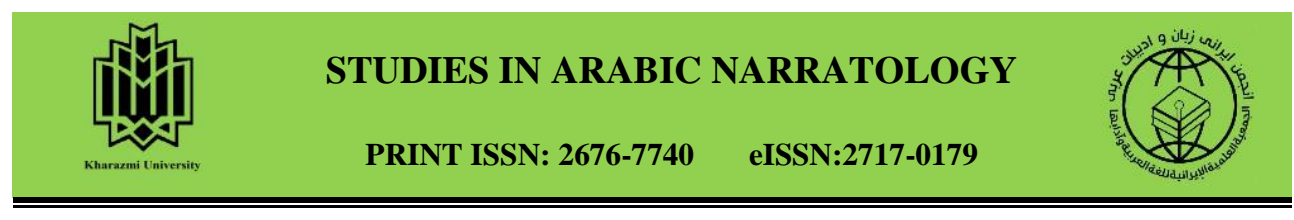

\title{
Partial Dichotomy in novel the birds of September of Emily
}

\section{Nasrallah}

Roghayeh Rostampour Maleki

r.rostampour@alzahra.ac.ir Associate Professor of Arabic Language and Literature, Alzahra University, Tehran, Iran.

Zahra Farid

z.farid@alzahra.ac.ir

Assistant Professor of Arabic Language and Literature, Alzahra University, Tehran, Iran. (Corresponding Author)

\section{Zahra Hosseini}

z.alhosseini@student.alzahra.ac.ir

MA Student of Arabic Language and Literature, AlZahra University, Tehran, Iran.

\begin{abstract}
Place is one of the most elements in a novel because it is a space where there are elements of the novel and the relationship established among them, including events. Also, it is an environment to form character and the element that completes the time of the story. "Place" in the novel has witnessed many changes in new studies and multiple different categories have been formed for it. The present study intends to investigate one of these categorizations- i.e., closed and open places (which is entitled spatial dichotomy or the confrontation between two opposing spaces and its effect on the characters of the story. The reason why we chose this novel was to examine the high frequency of open or closed places such as houses, schools, cities, and villages in the novel. One of the most important results is a wide-ranging description of the closed spaces due to the living problems and personality disorders of the novel characters. Moreover, the novel indicates that open places are not always a source of happiness and well-being for the characters, rather psychological and material consequences and effects of these places may differ in person's perspective to that place. The method applied in the study is a descriptive-analytical one, based on the description and analysis of the data derived from the context of the novel.
\end{abstract}

Keywords: Novel, Partial Dichotomy, Character, Emily Nasrallah, The birds of September, Arabic Narratology.

Citation: Rostampour, R; Farid, Z; Hosseini, Z. Spring \& Summer (2020). Partial Dichotomy in novel the birds of September of Emily Nasrallah. Studies in Arabic Narratology, 1(2), 143-165. (In Arabic)

Studies in Arabic Narratology, Spring \& Summer (2020), Vol. 1, No.2, pp. 143-165

Received: July 1, 2020; $\quad$ Accepted: September 2, 2020

CFaculty of Literature \& Humanities, University of Kharazmi and Iranian Association of Arabic Language \& Literature. 


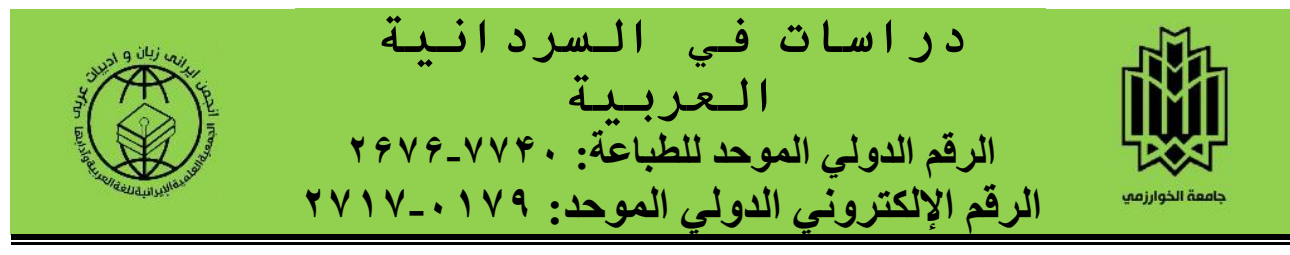

\section{الـتقـاطب الـمكـانـي في رواليـة طيـور أيـلـول لإمــــي نـــر الله}

r.rostampour@alzahra.ac.ir البريد رقيه رستم بور ملكي

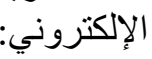

أستاذة مشاركة في قسم اللغة العربية و آدابها بجامعة الزئزئ هراء، طهر ان، ايران. z.farid@alzahra.ac.ir

$$
\text { زهراء فريد }
$$

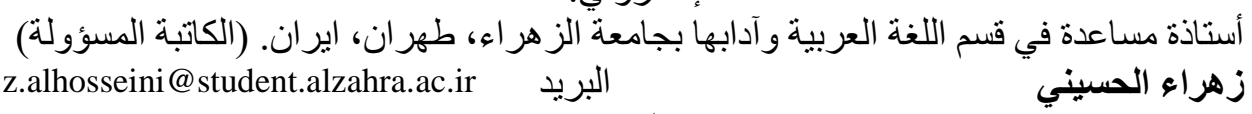

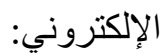

طالبة مرحلة الماجستير في قسم اللغة العربية وآدابها بجامعة الزهر اء، طهر ان، ايران.

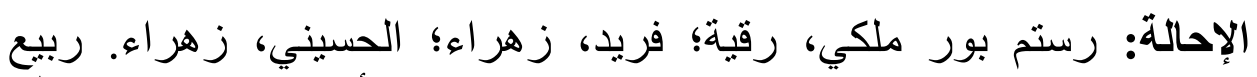

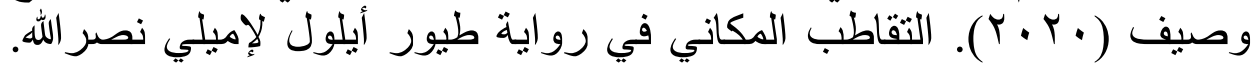

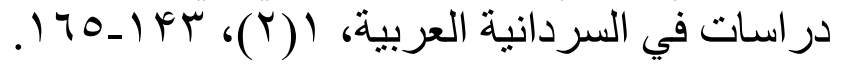

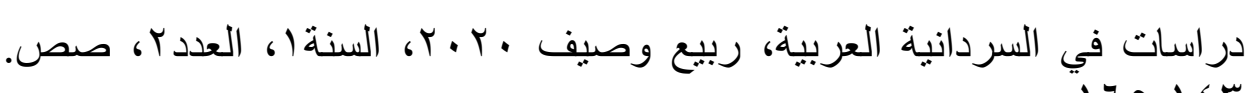
. $170.1 \leqslant \mu$

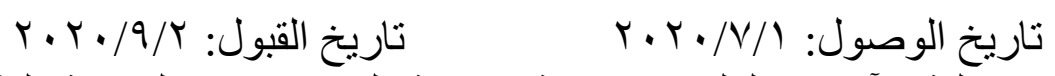

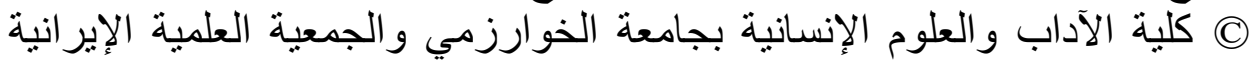
للغة العربية و آدابها.

$$
\text { الـمـلخهم }
$$

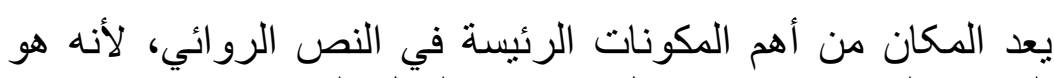

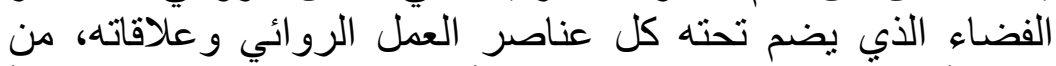
حيث أنه الٔموقع الذي تدور فيه الأحداث وهو في الواهي اقعل، ملجأ 
للشخصيات وهو من العناصر المكملة للعنصر الزماني في الرواية. وقد شهد المكان العديد من التطور ات الحديثة في الدر اسات المنات المعاصرة

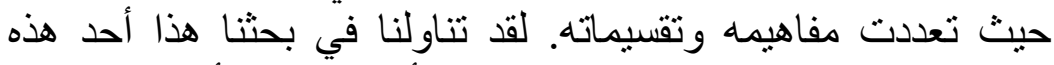

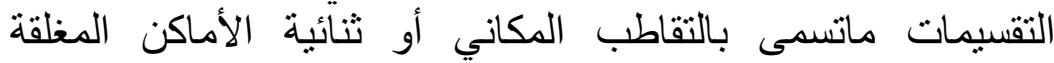

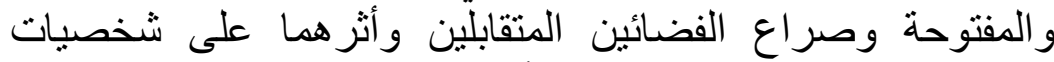

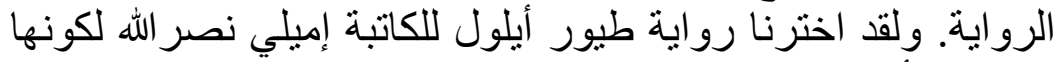

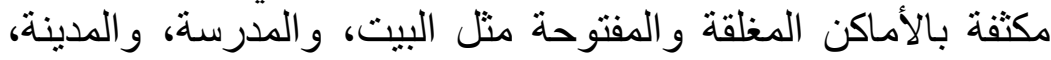

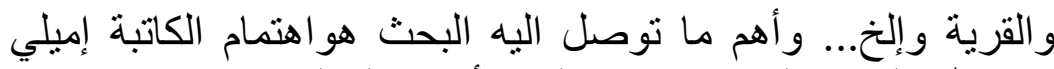

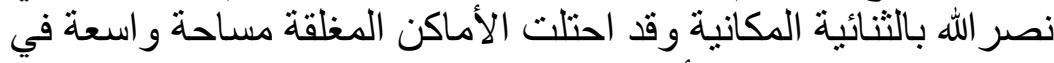

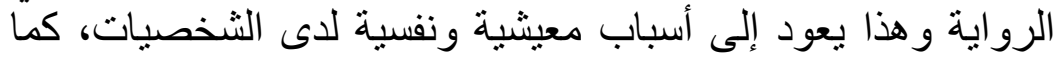

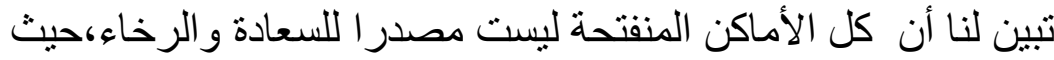

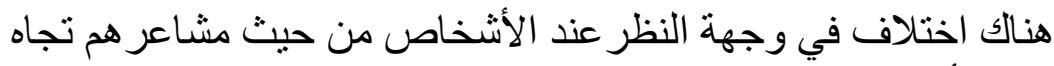

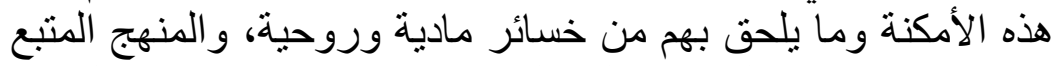

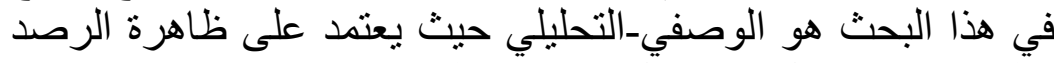
و الوصف و التحليل من خلال الوقوف على نماذج مختارة من الرواية.

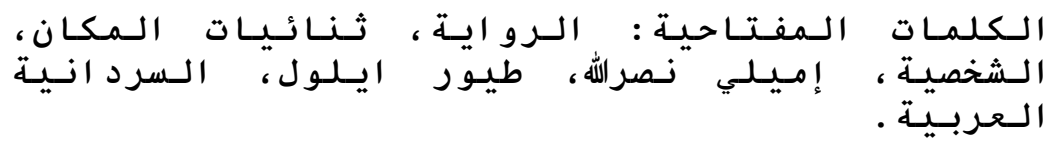




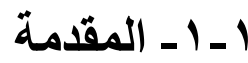

لقد اهتم نقاد العرب بعنصر المكان في الأدب بشكل عام وفي الرواية بشكل

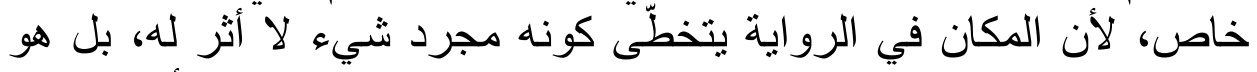

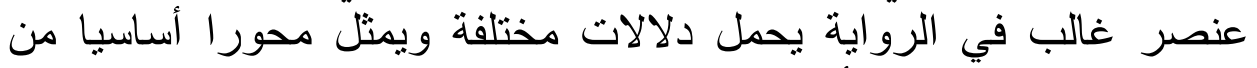
محاور الرواية بعطيها الأصالة. فئرائ.

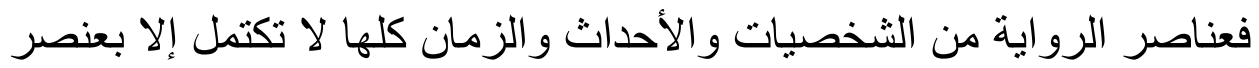

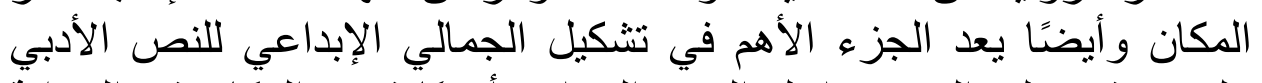

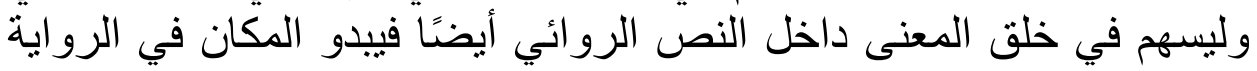

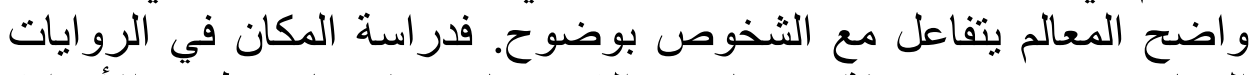
المعاصرة تسبب معرفة خصائص الثخصبات وفهمها وتطور الثور الأحداث

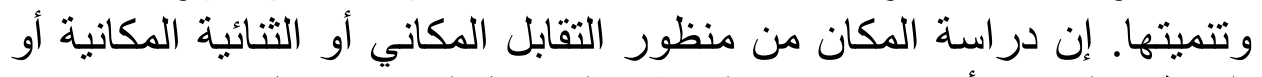

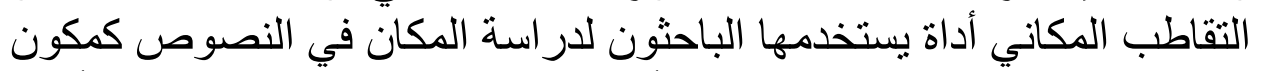

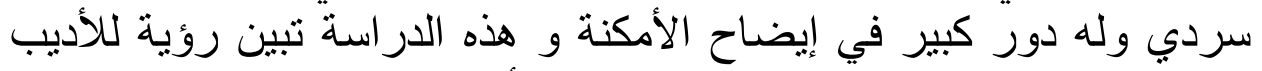

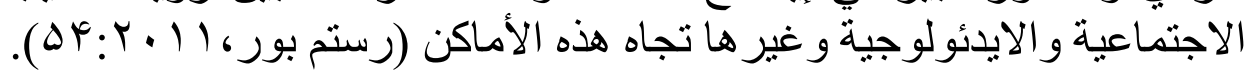

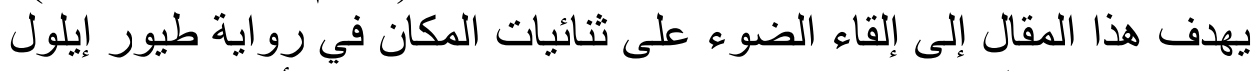

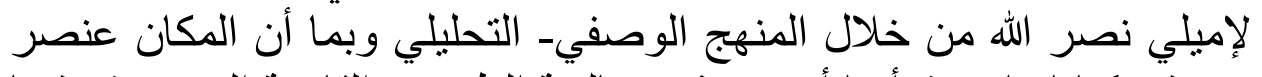
مهم في كتاباتها حيث أنها أسهبت في معالجة الظروف فئ القاسية التي تعيش فيها

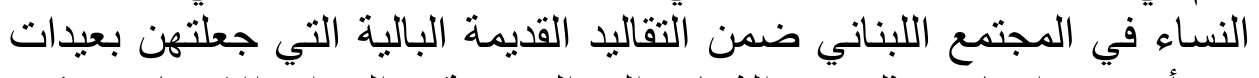

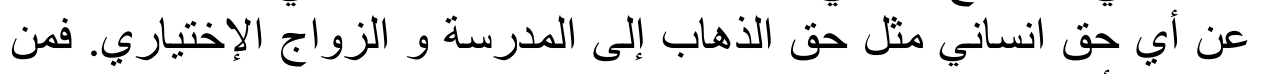

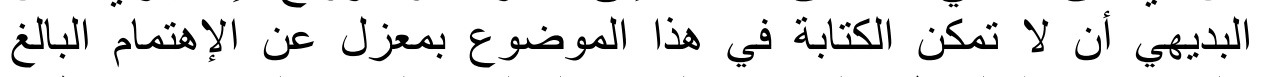

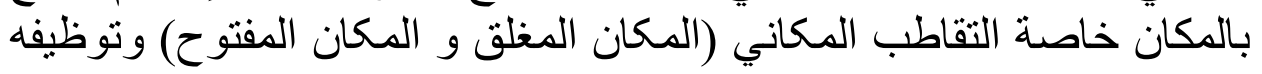

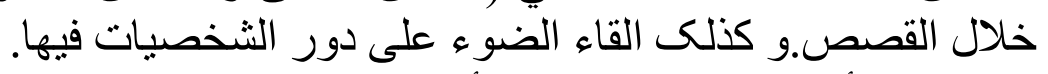

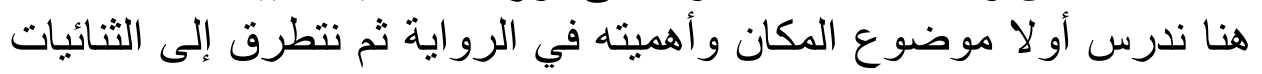

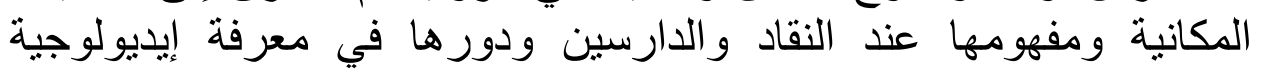
المؤلف ثم ننتقل إلى در اسة ثنائيات المكان في روايتنا هذه للتعرف فئ على دلى دلالة المكان و التشكيل الفني للفضاء فئهاء

تهدف هذه الدر اسة إلى البحث عن الأمكنة المفتوحة و المغلقة التي استدعتها

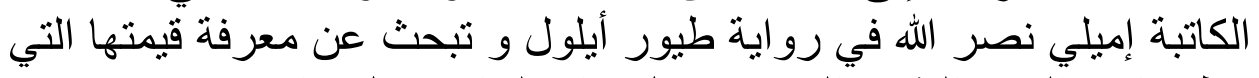
وظفتها في النص النثري العربي بشكل عام ولبنان بشكل خاص. 


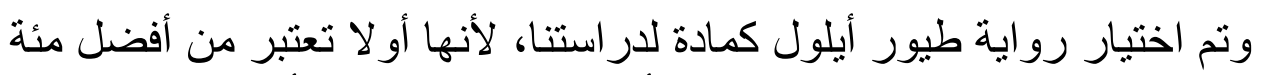

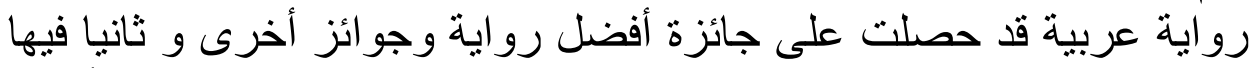

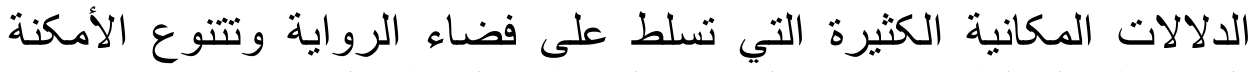
المفتوحة و المغلقة فيها، منها البيت، الئرة والمدينة، و القرية و إلخاه...

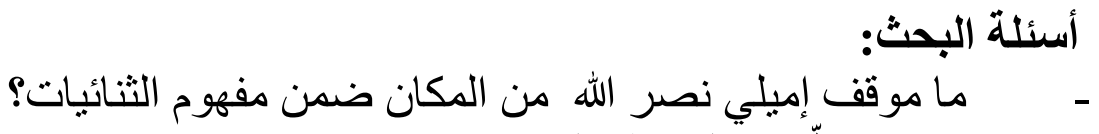
و أحداثها؟ خلقيه البحث : والبه ومن الأبحاث التي قد تناولت الأعمال الأدبية لإميلي نصر الله رسالة ماجستير

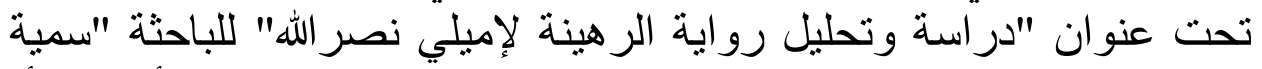

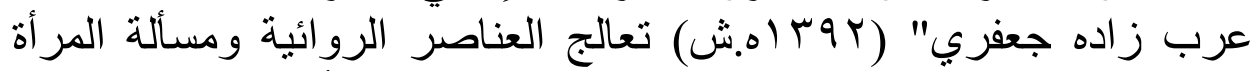

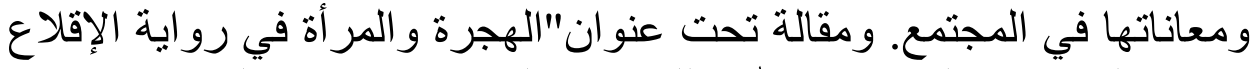

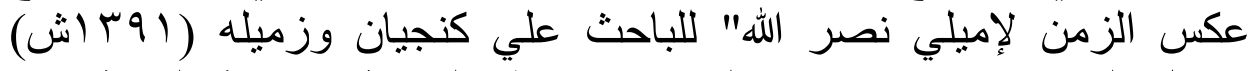

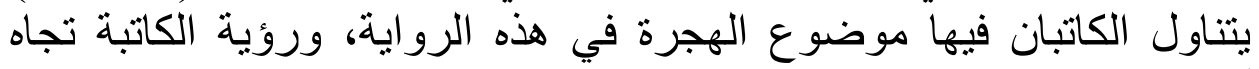

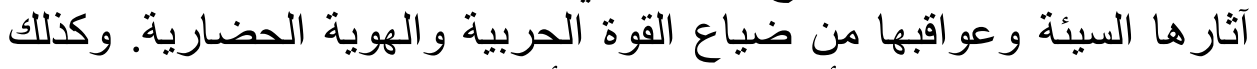

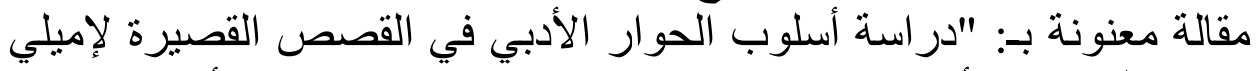

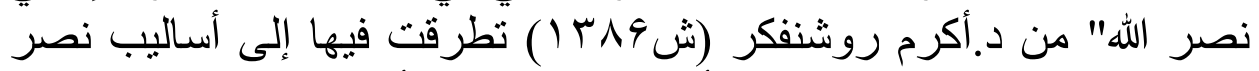

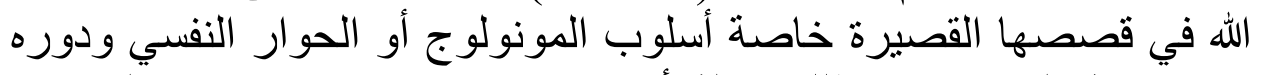

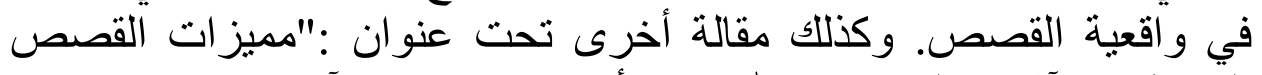

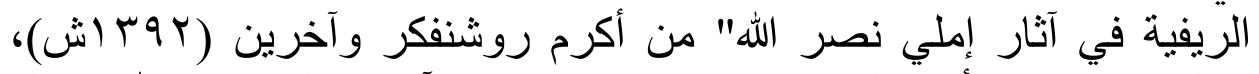

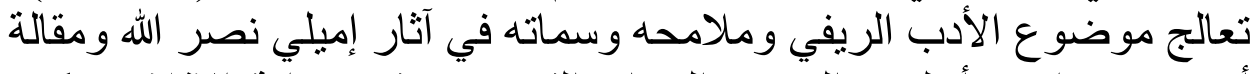

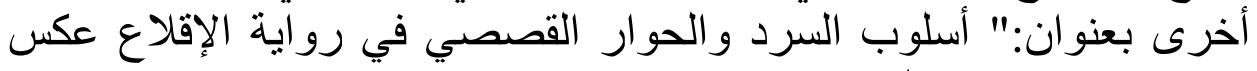

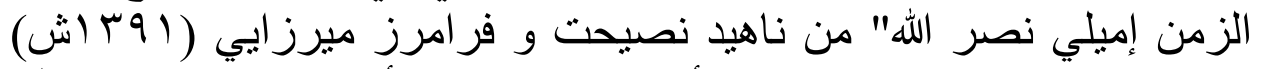

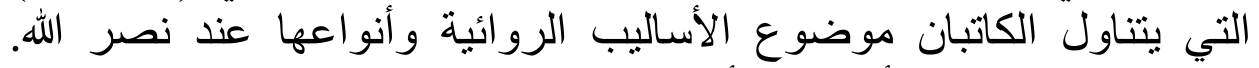

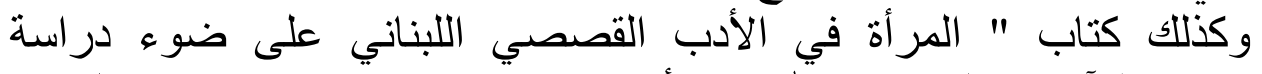

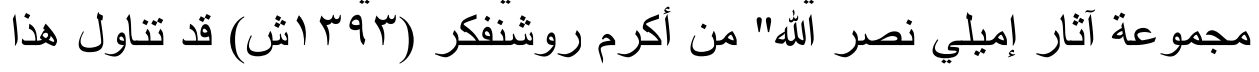

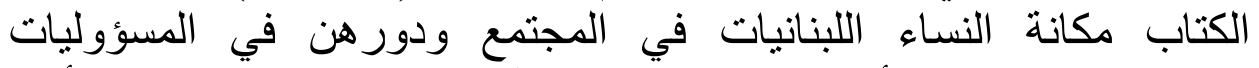

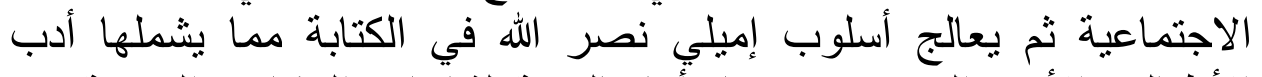
الأطفال والأدب الريفي وغير ها. أُما بالنسبة لثنائيات المكان والضدية بين الضين 


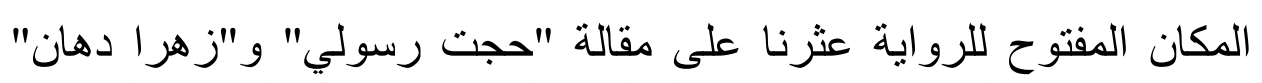

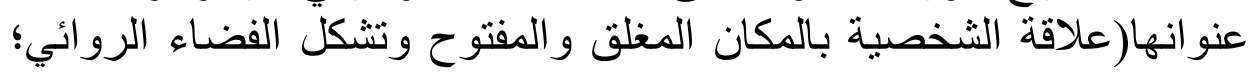

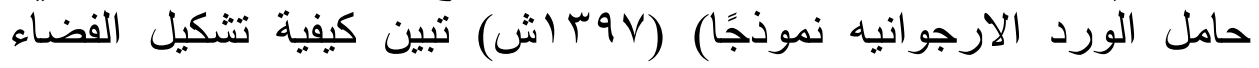

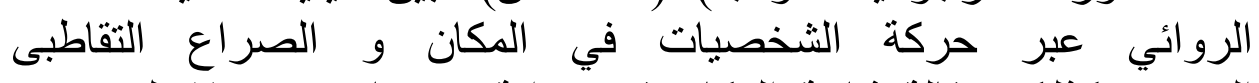

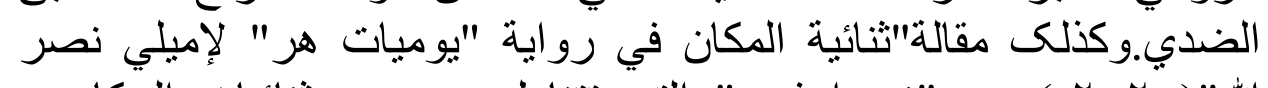

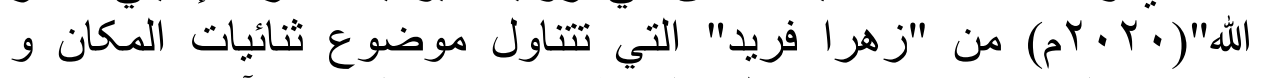

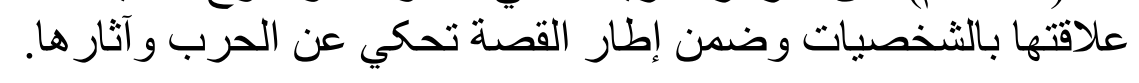

نبذة عن حياة المؤلفة:

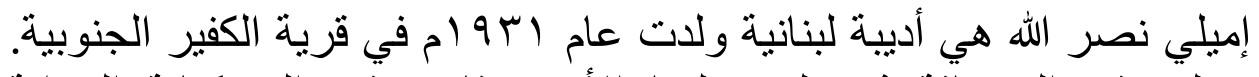

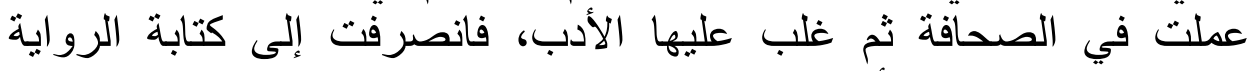

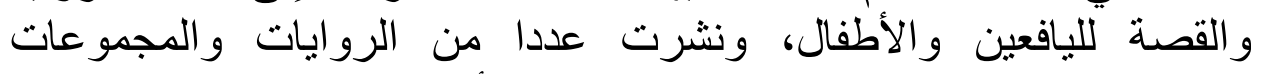

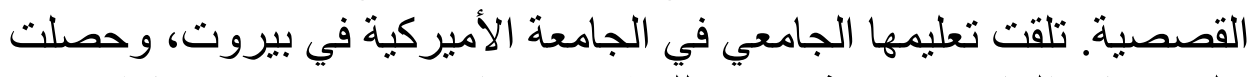

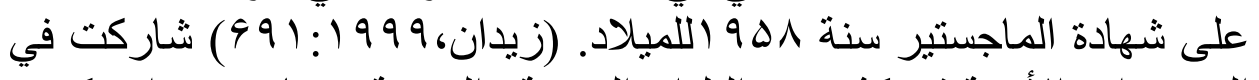

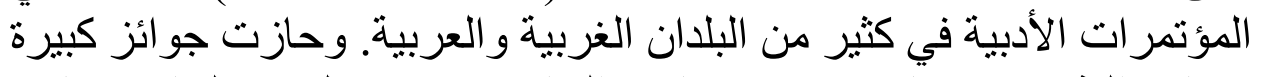

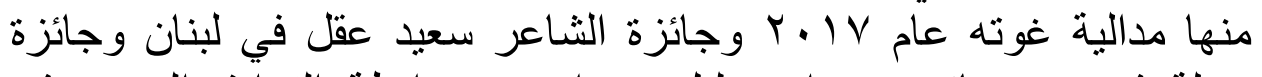

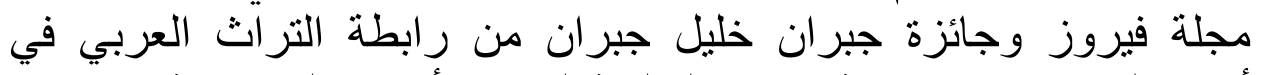

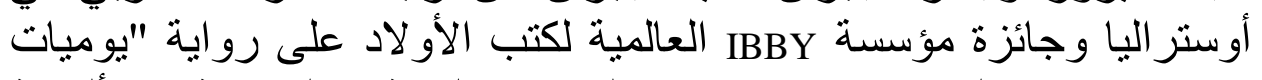

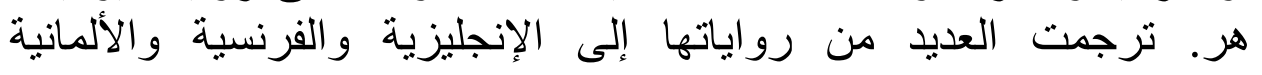

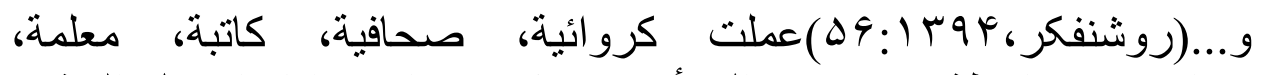

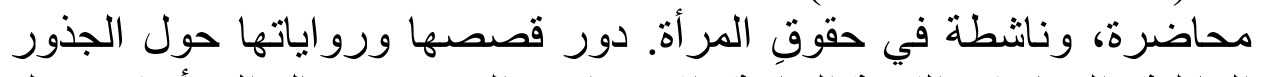

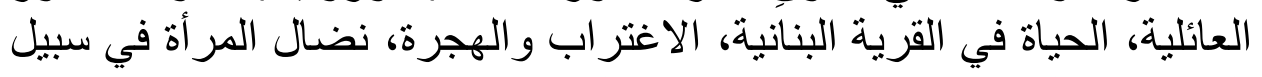

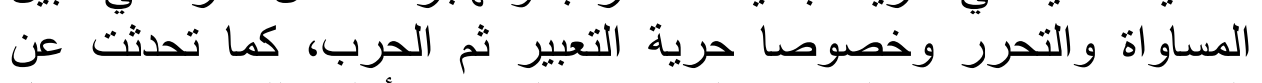

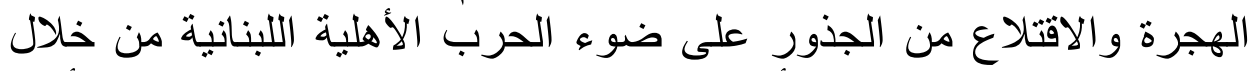

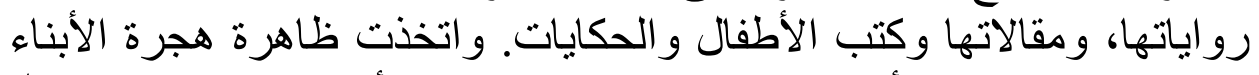

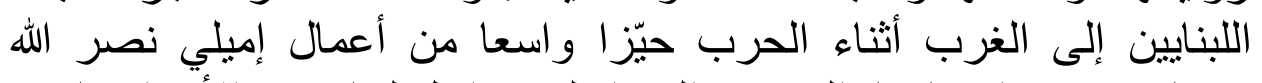

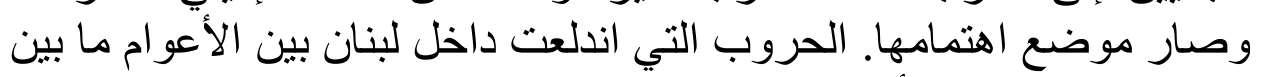

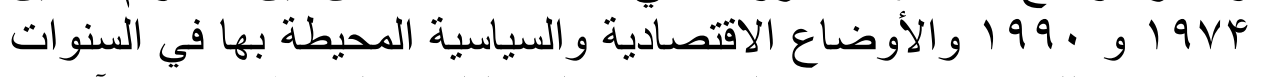

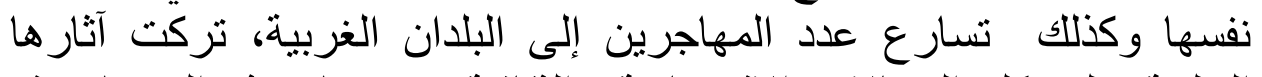

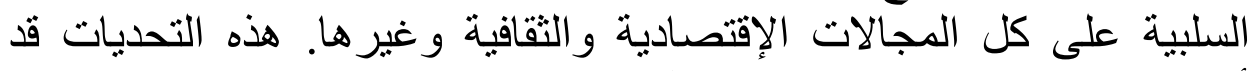

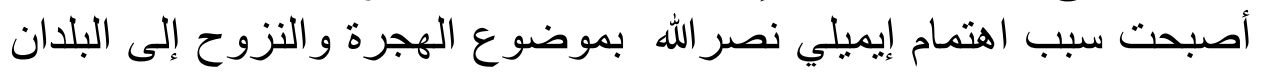




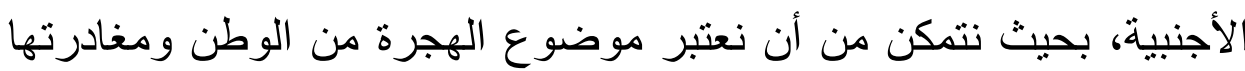

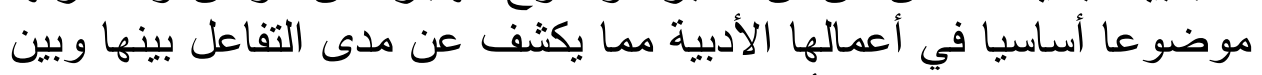
وطنها اللبناني من حيث أنها بيت عريق جمعت الادية فيكا فيه الطبقات الاجتماعية

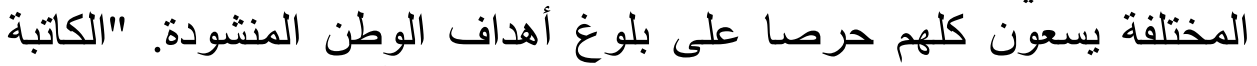

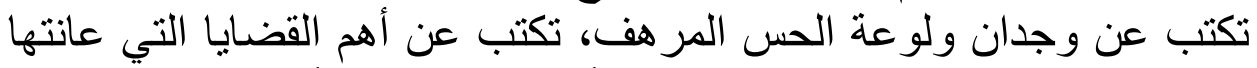

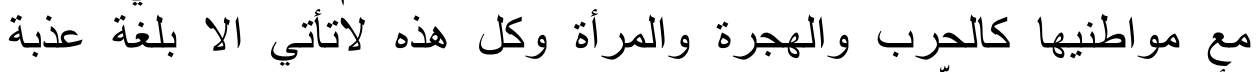

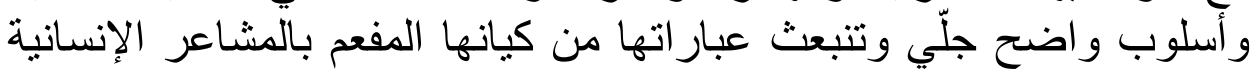

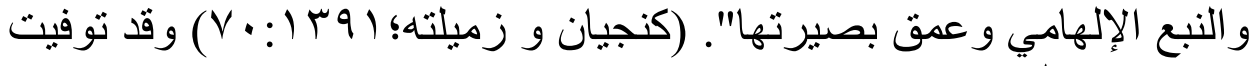

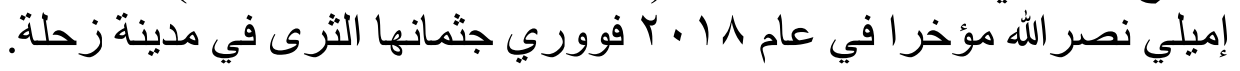
ملخص رواية طيور أيلول

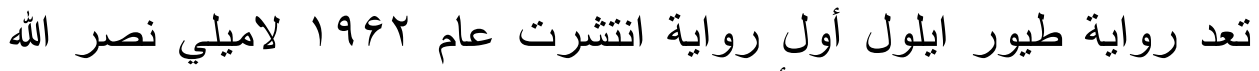

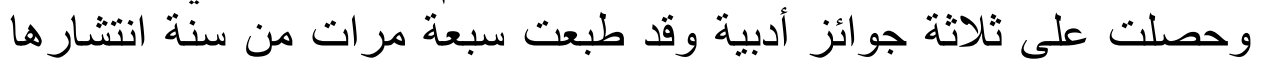

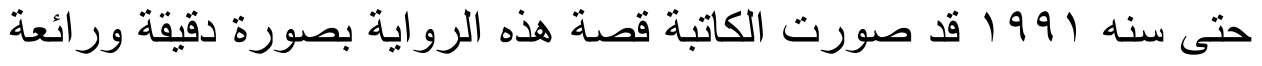

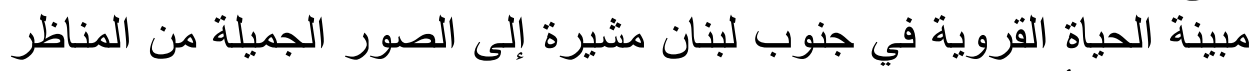

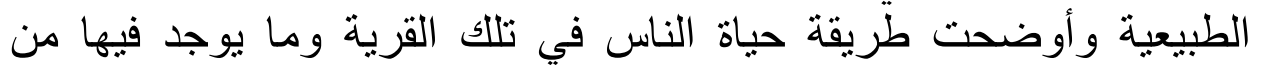

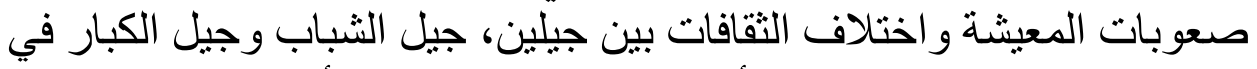

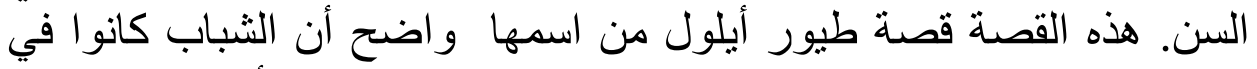

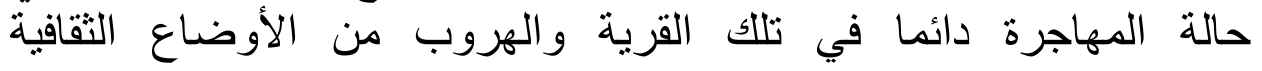

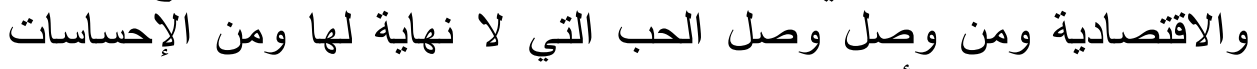

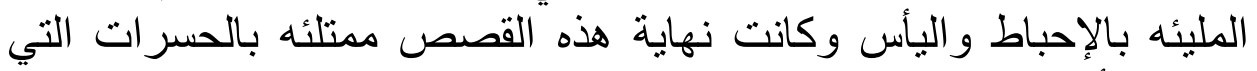

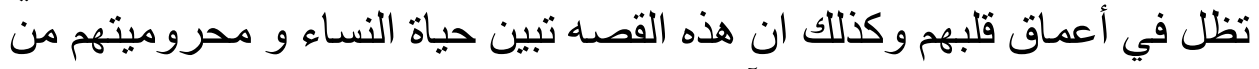

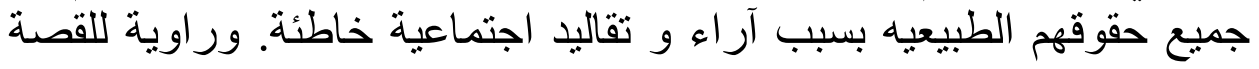

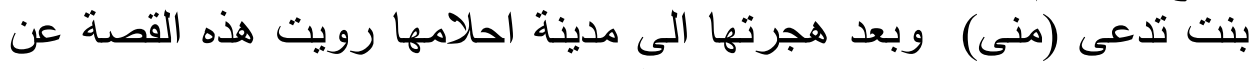

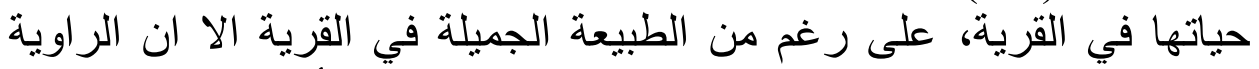

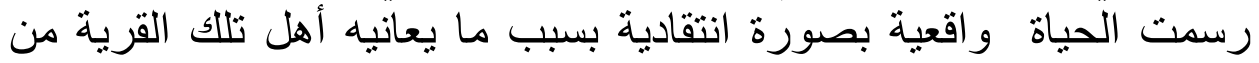

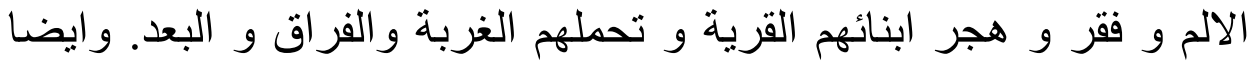

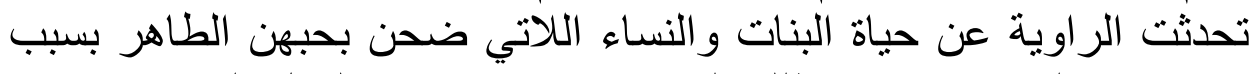

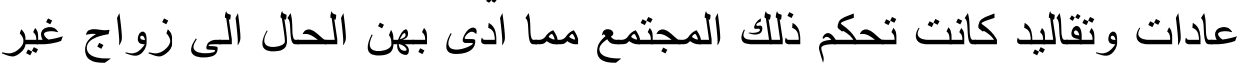

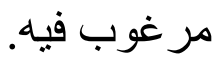
أهمية المكان في بناء الرواية: - مغية 


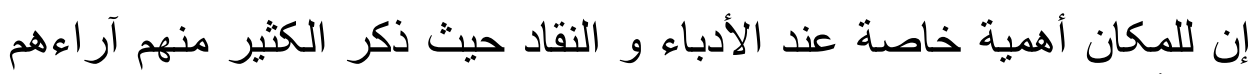

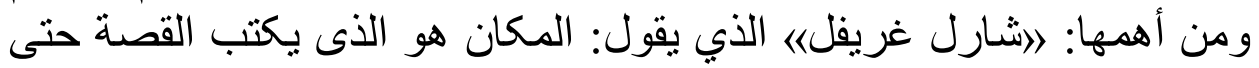

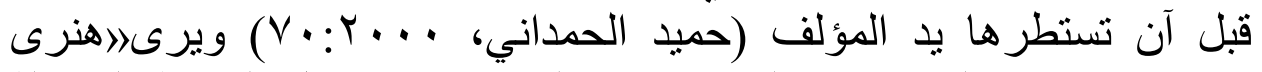

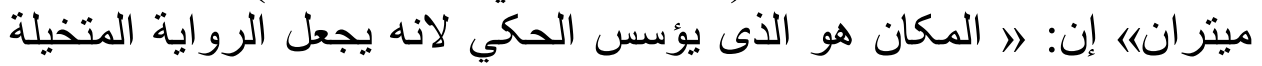

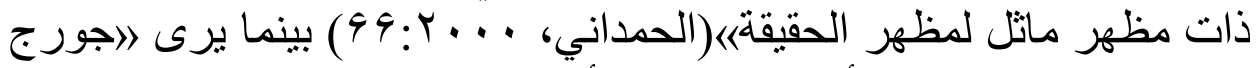

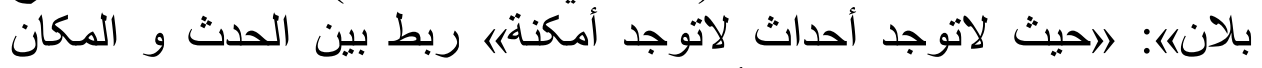

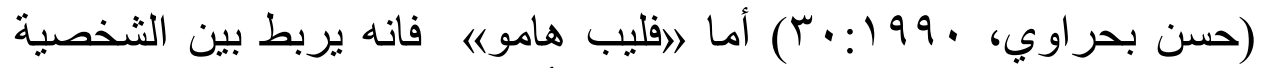

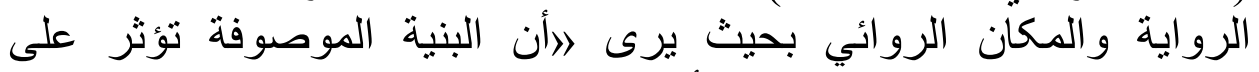

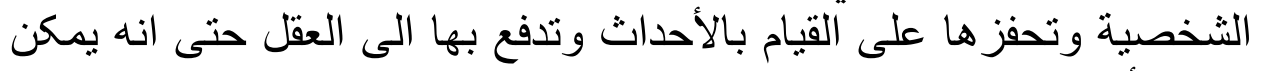

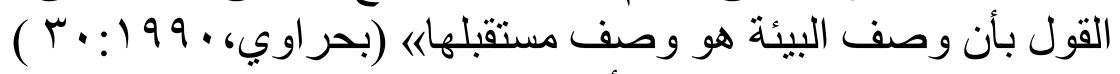

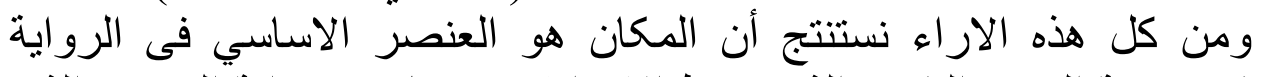

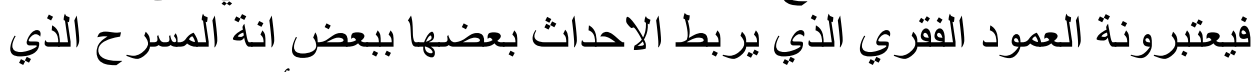

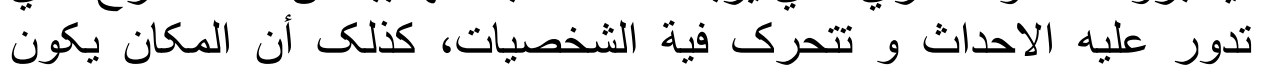

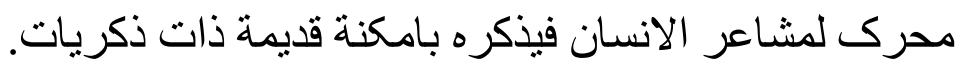

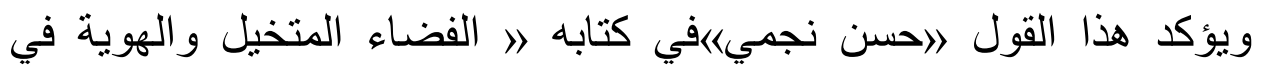

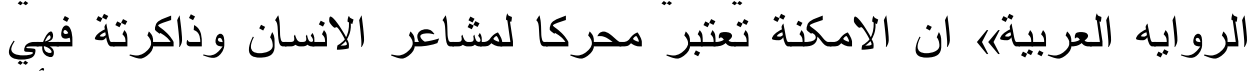

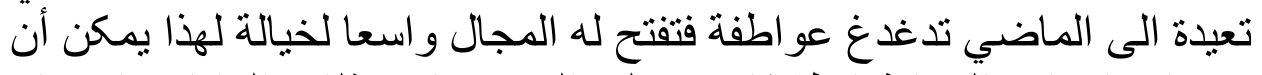

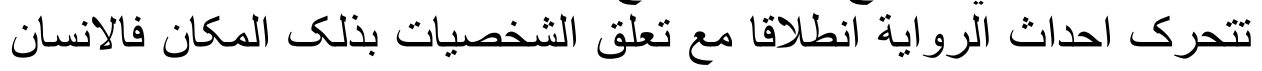

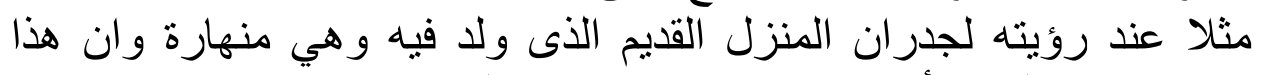

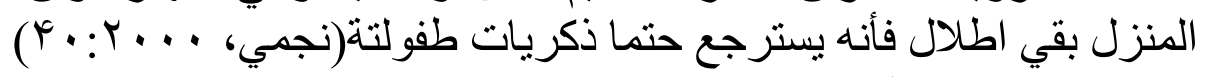

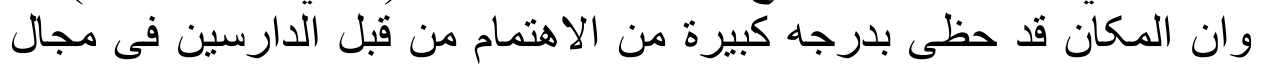

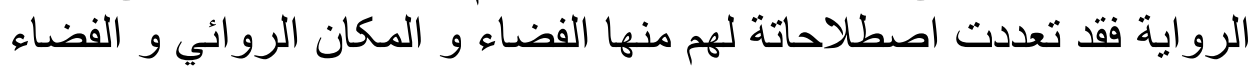

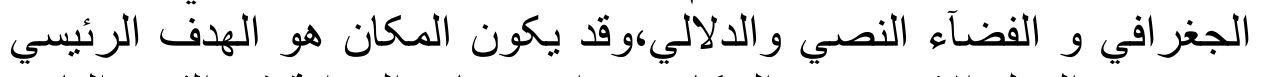

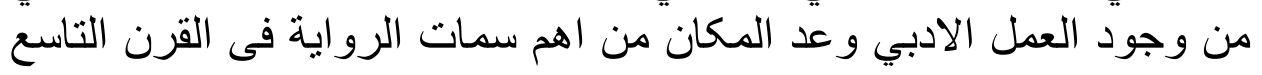

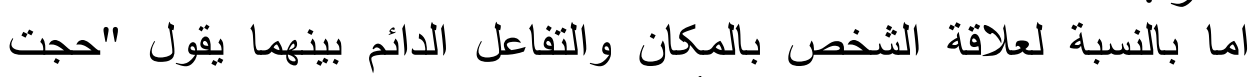

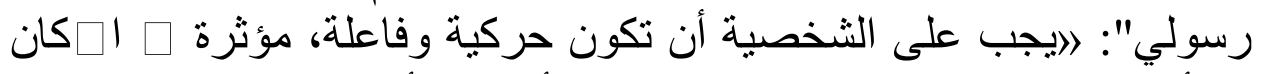

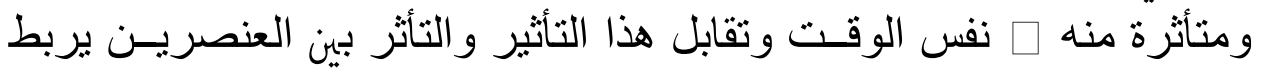

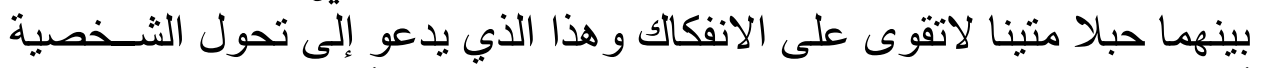

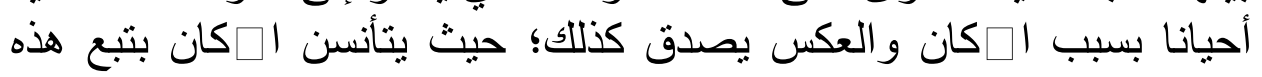

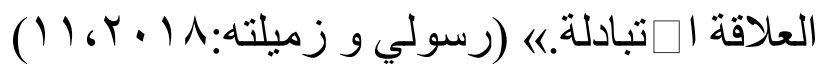




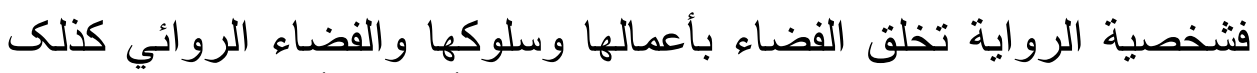

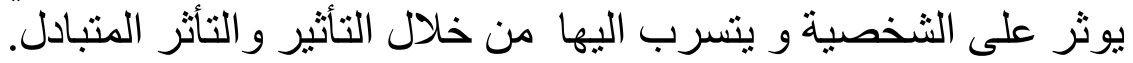

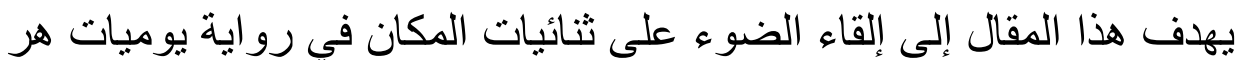

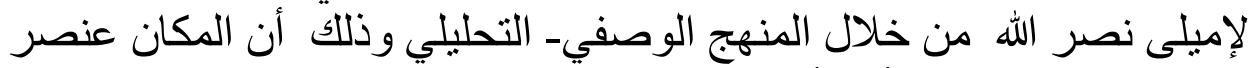

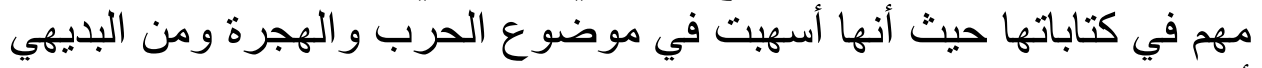

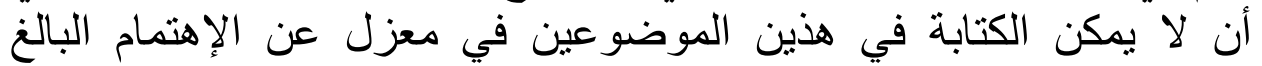

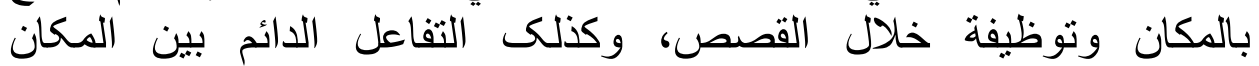
و الثخصيات من حيث الايدئولوجية و وجهة النظر تجاه العالم و حو ادثها.

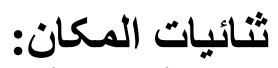
من الأفضل أن نتطرق إلى موضوع الثنائية أو التقاطب المكاني من خلال

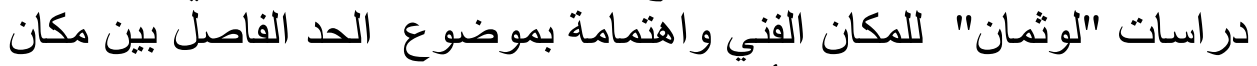

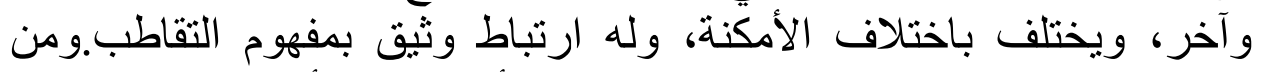

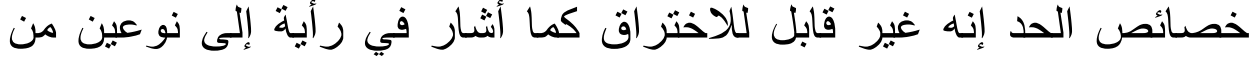

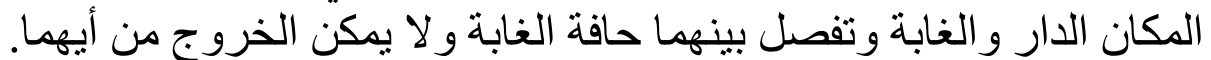

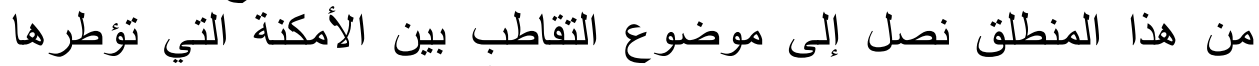

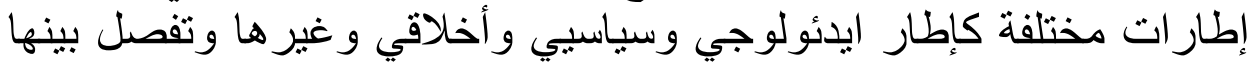

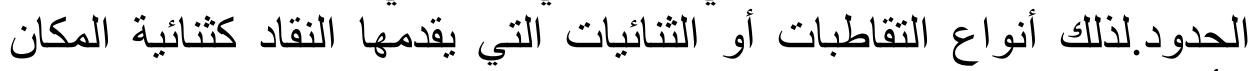

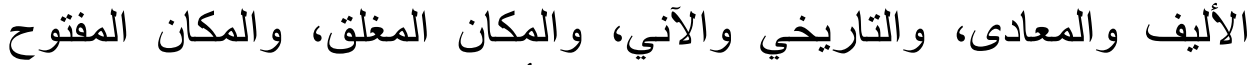

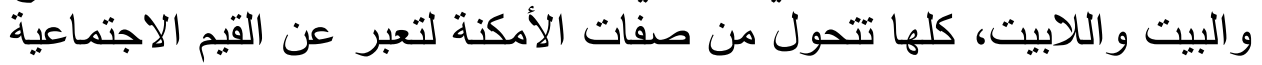

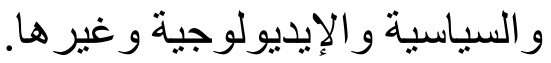

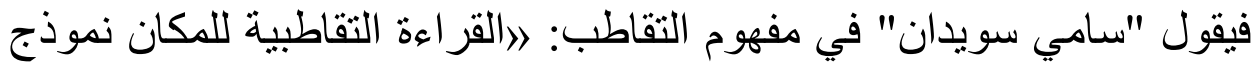

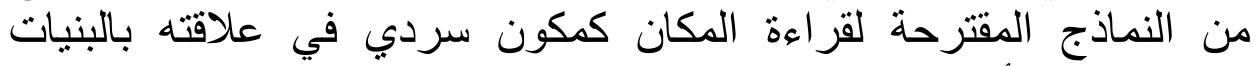

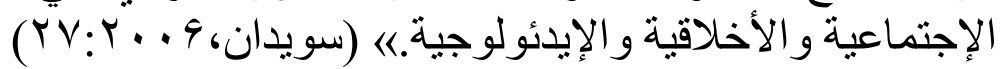

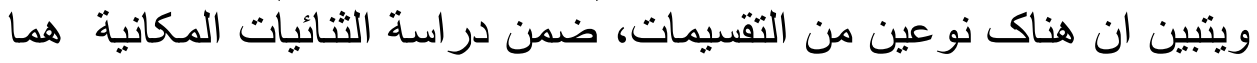

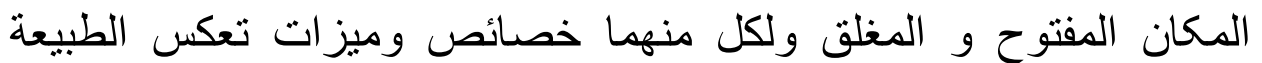

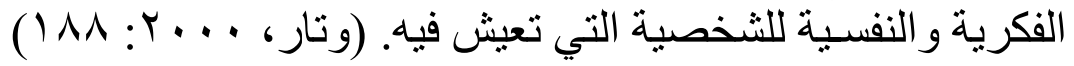

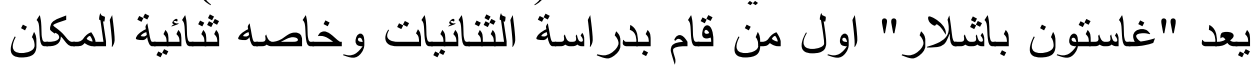

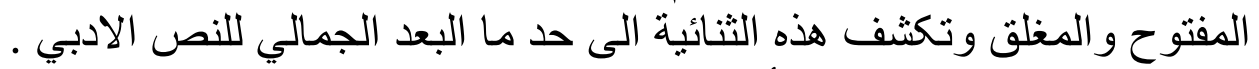

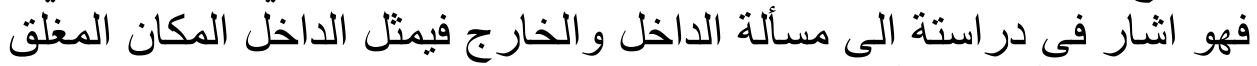

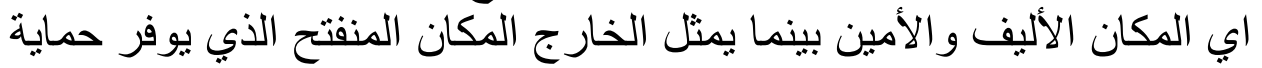




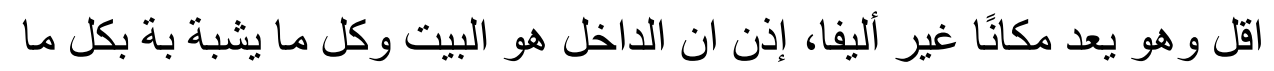

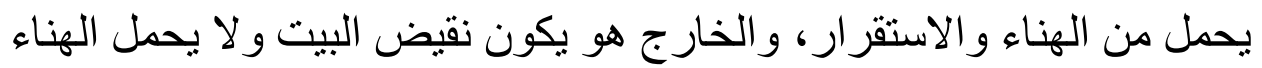

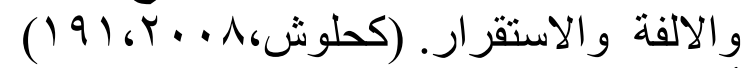

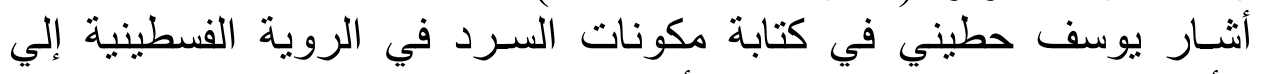

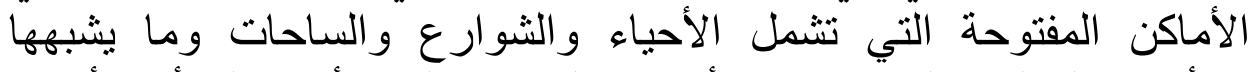

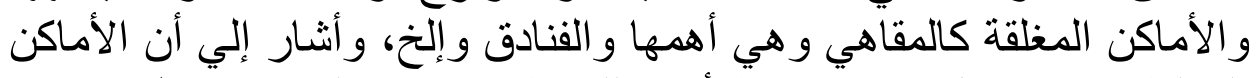

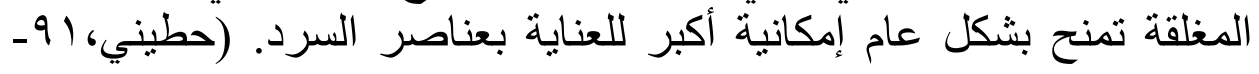

(1999:9

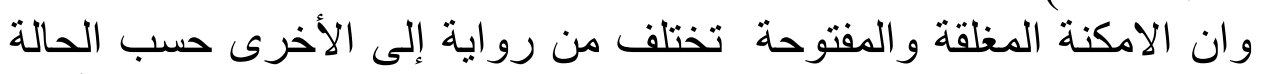

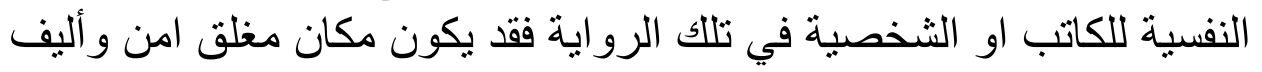

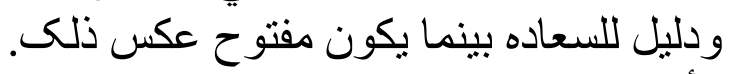

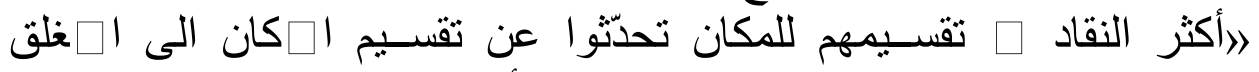

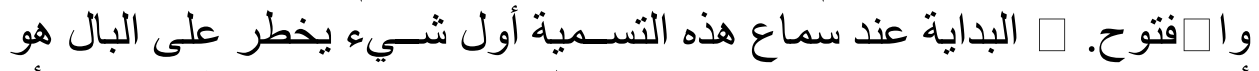

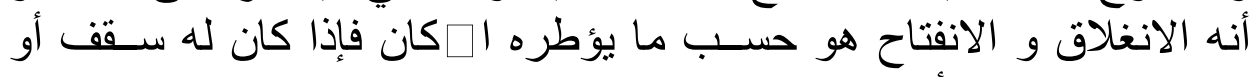

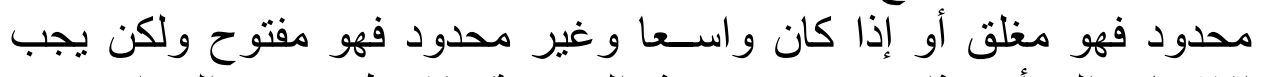

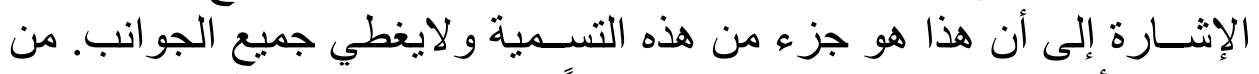

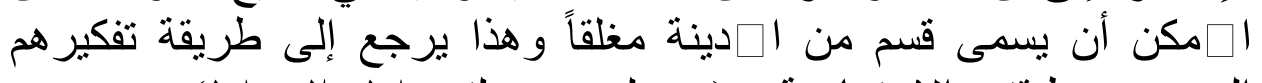

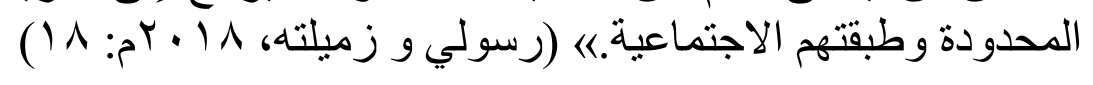
الاماكن المفتوحة و المغلقة في رواية طيور ايلول

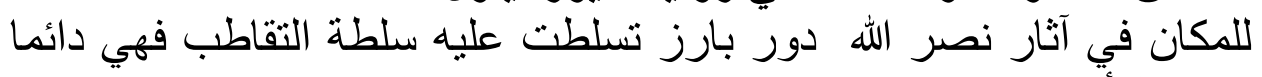

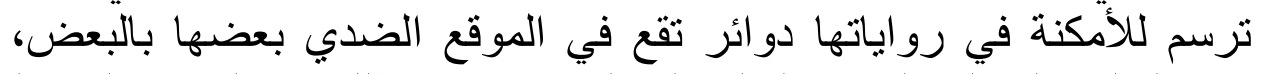

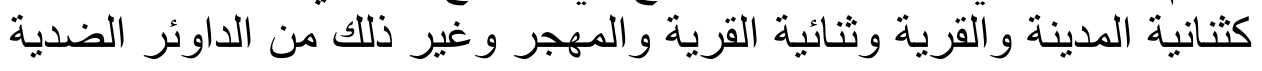

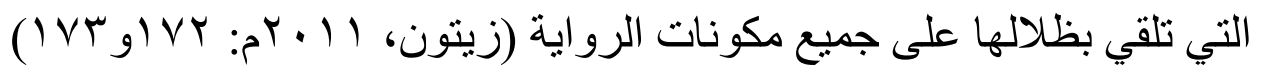

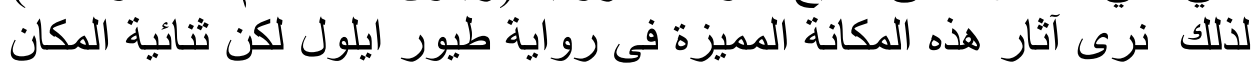
فيها تلعب دور ا بارزا.

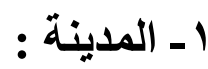

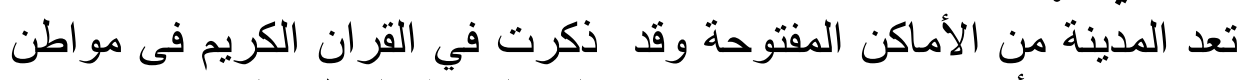

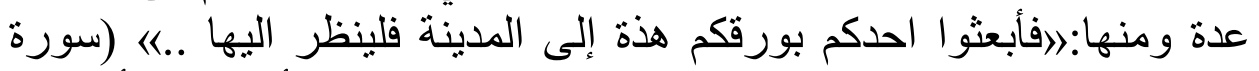

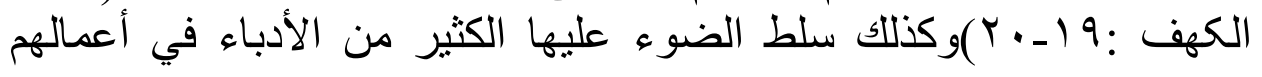


الأدبية و كانت مصدرًا للمواضيعهم ويعود هذا الاهتمام بالمدينة نتيجة| هتمامهم بالثقافات الغربية.

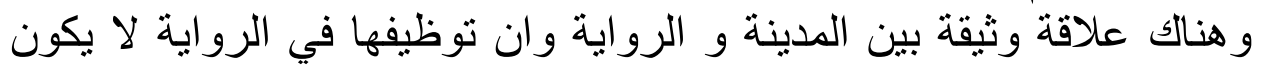

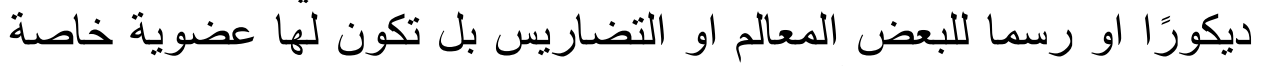

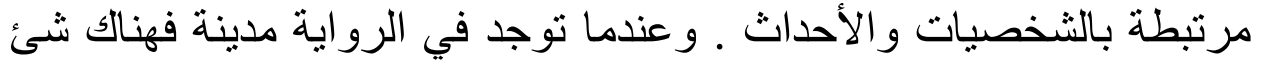

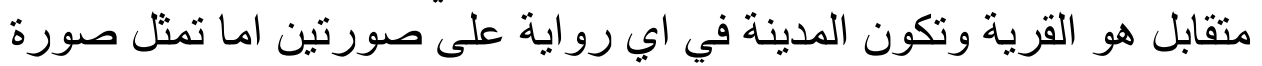

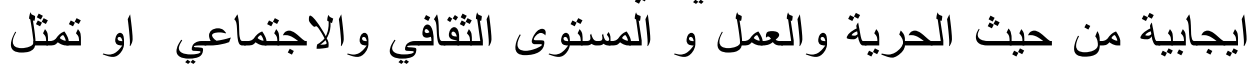

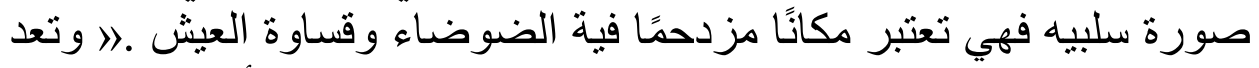

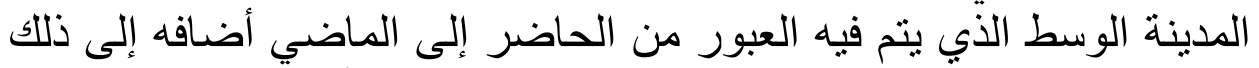

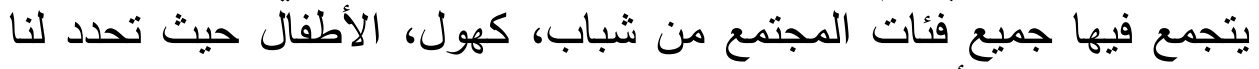

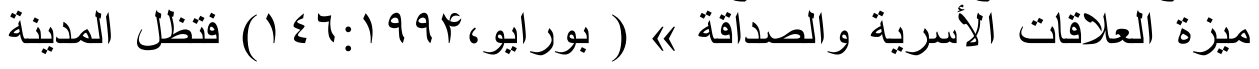

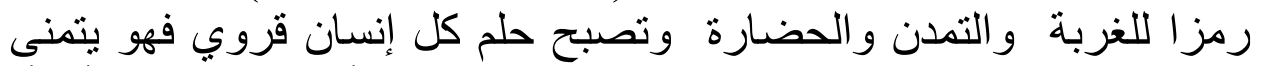

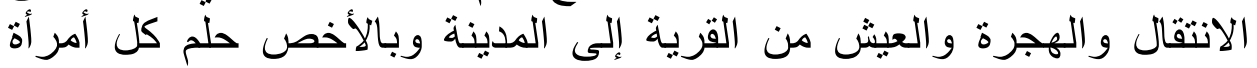
عانت من الظروف القاسية في القرية. تمثل المدينة في هذة الرواية (طيور أيلول) ليست مكانا مجردا، انما فضاء

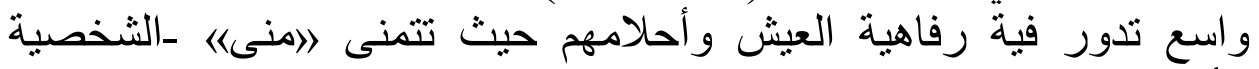

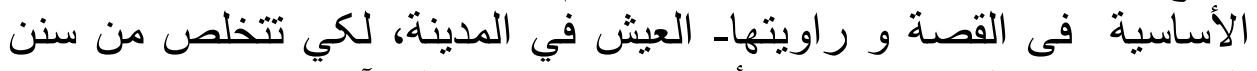

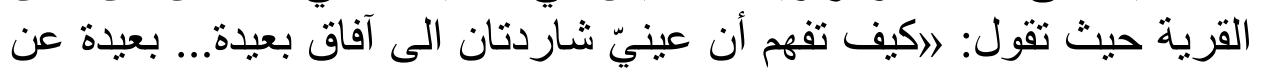

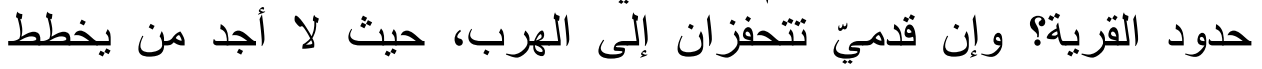

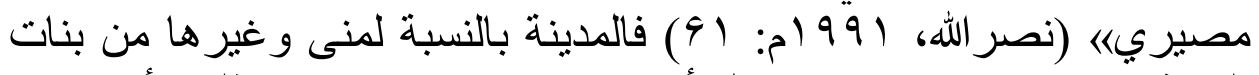

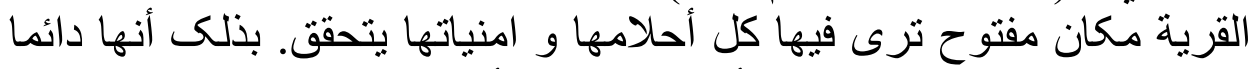

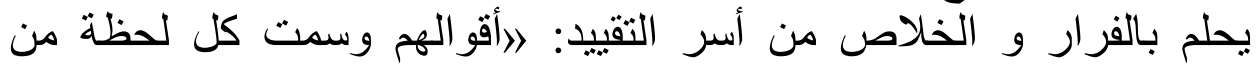

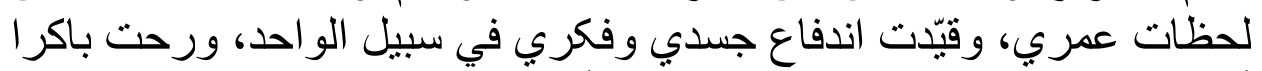

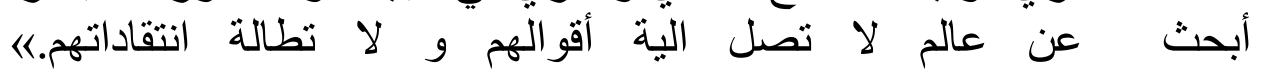

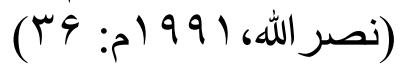

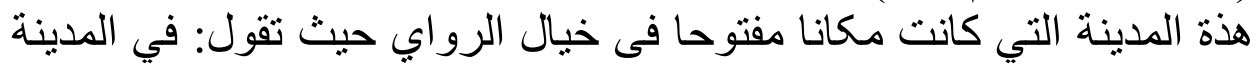

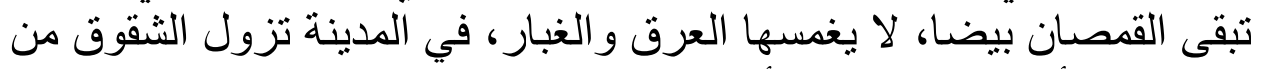

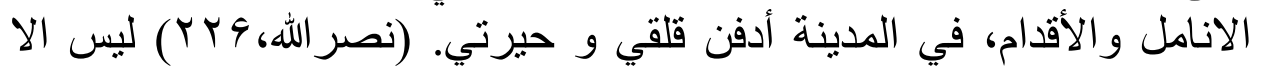

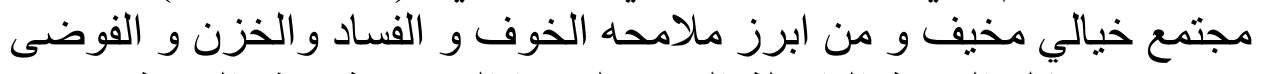

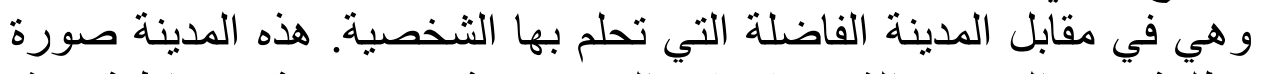

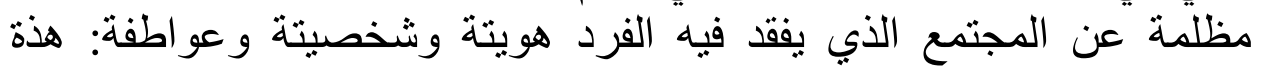


الصورة التي تصفها الراوية ساعة وصولها الى المدينة:"بصقتني السيارة فى ولى

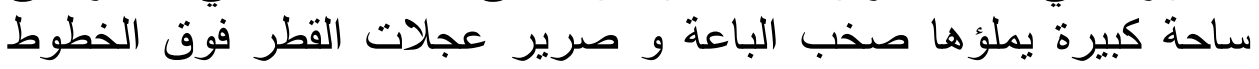

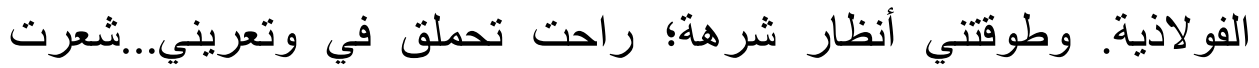

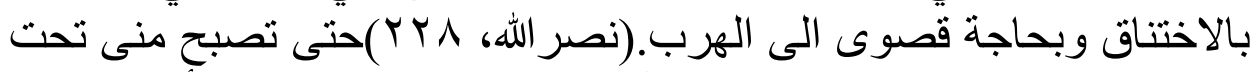

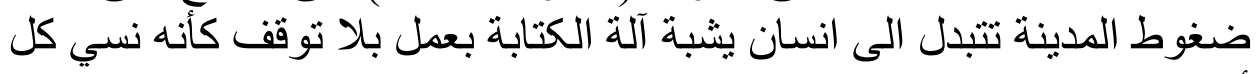

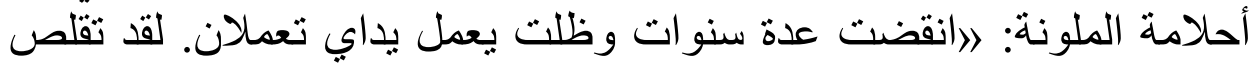

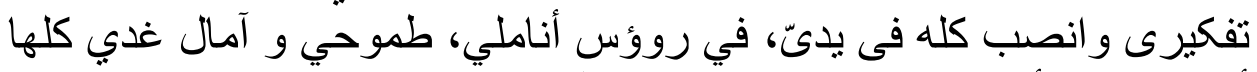

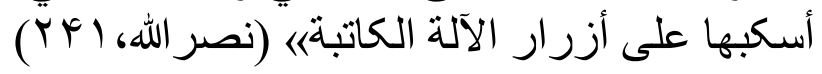

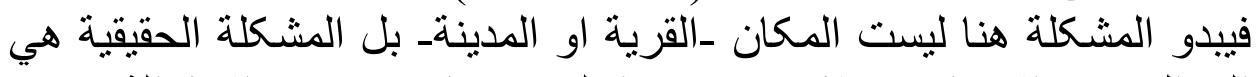

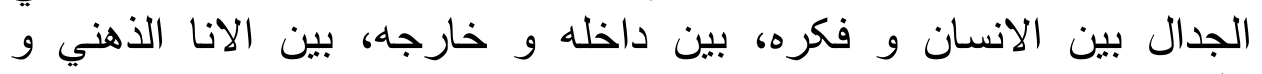

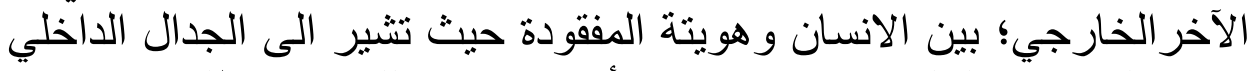

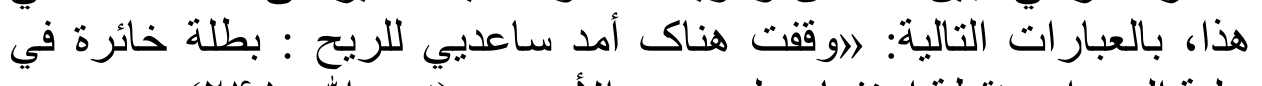

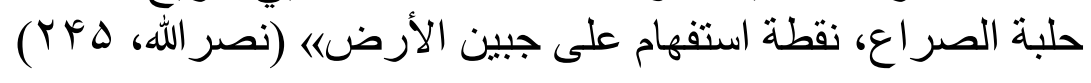

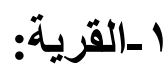
القرية او الريف بكل ما فية من جمال و صفاء وطبيعة خلابة وطيور مغردة

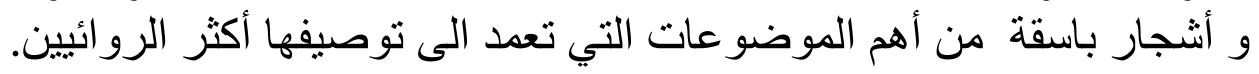

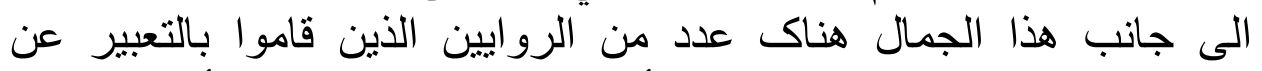

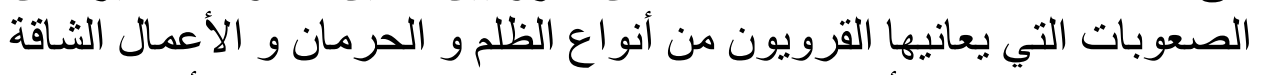

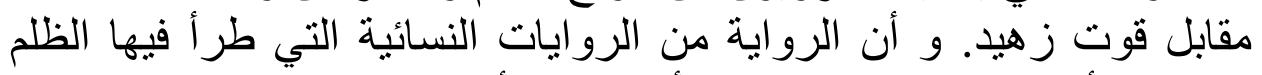
على المرأة في المجتمع القروي، فأصبح من أهم من موضو الفئ عاتها او العدود الفقري فيها. تعد القرية في روايتنا هذة، واحدة من الأماكن المغلقة المحدودة بحدود

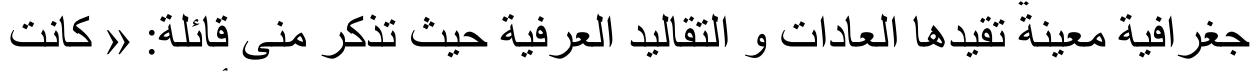

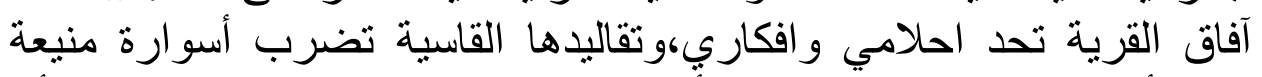

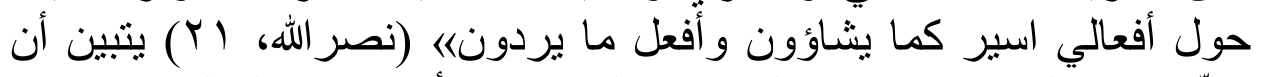

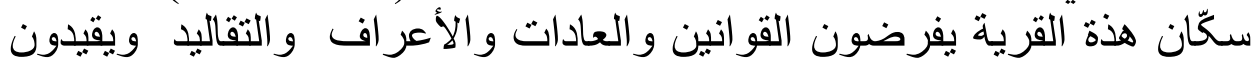

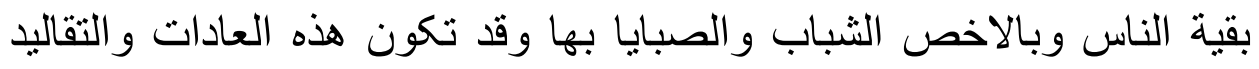

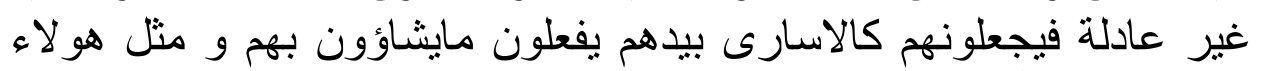

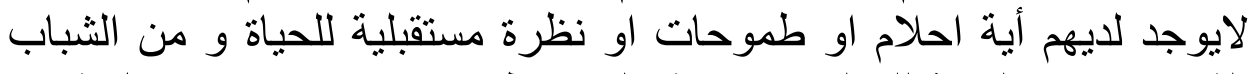
الأين هاجروا القرية للتخلص من هذة الضغوطات هو راجي اجي حيث يقول ذاكرا 
الى مرسال: / مرسال، ان حدود القرية تضغط اعصابي تكاد تقتلني، انا

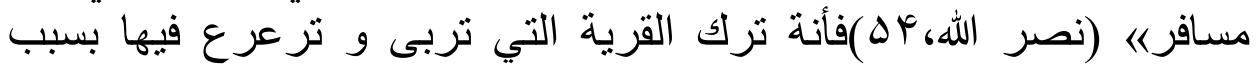

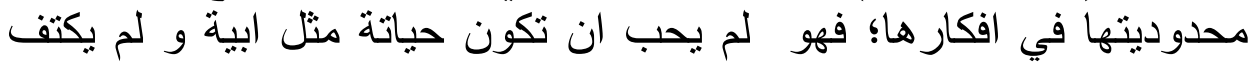

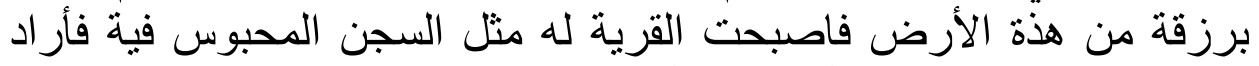
الهجرة الى المدينة ليحقق أحلامة و أهدافة الهة الهن 》الان القرية في منظومة اميلي نصر الله الفكرية تكون كرحم يؤمن الحماية

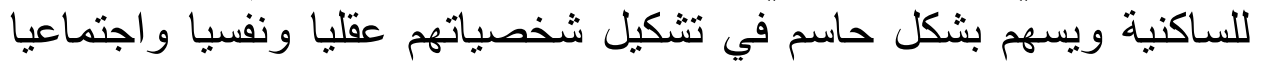

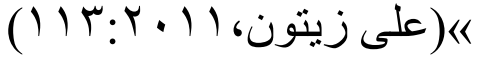

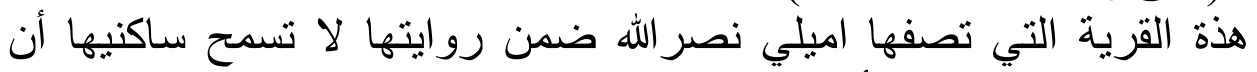

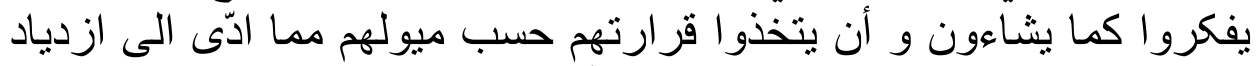

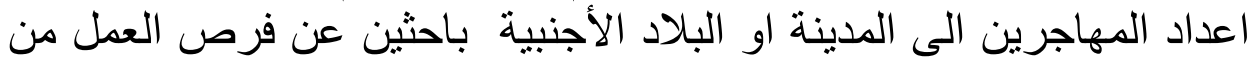

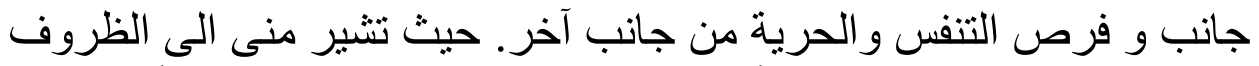

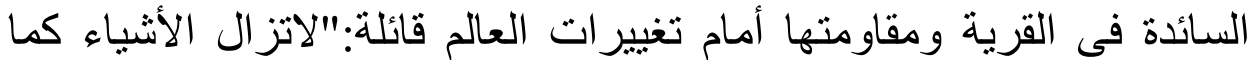

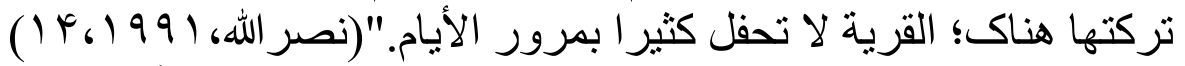

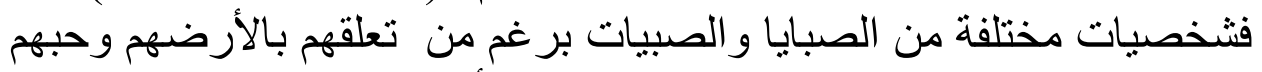

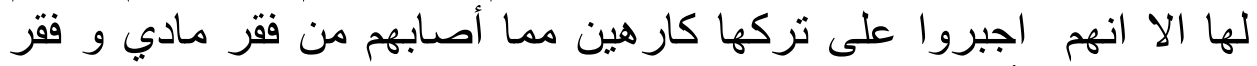

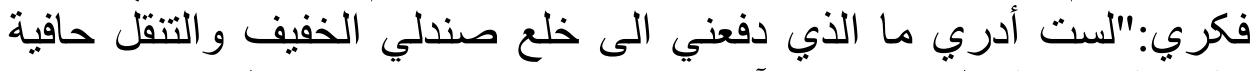

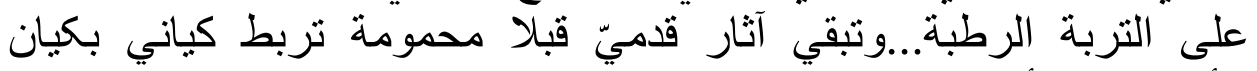

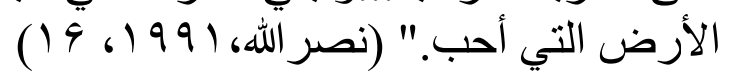

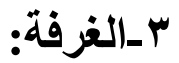

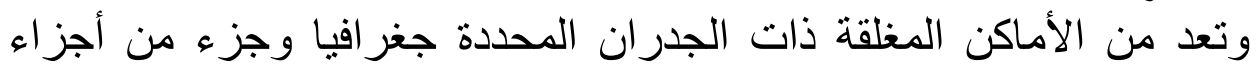

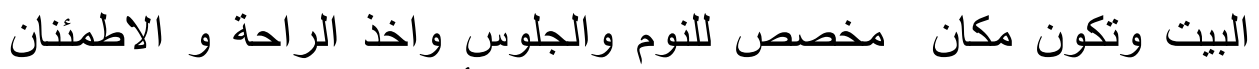

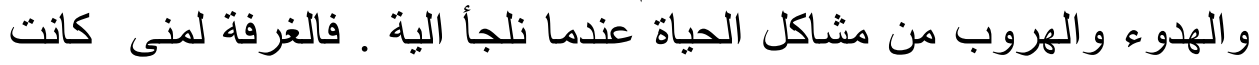

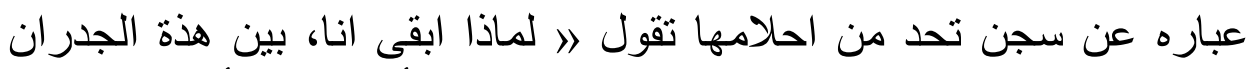

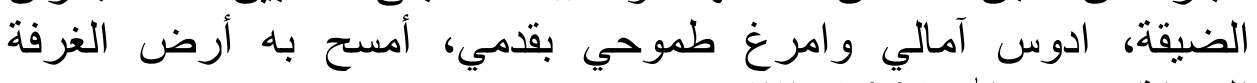

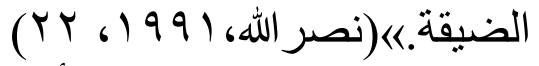

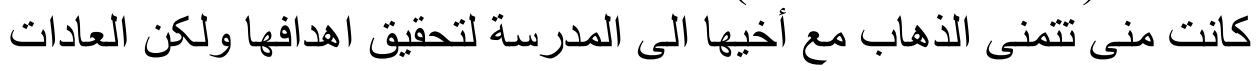

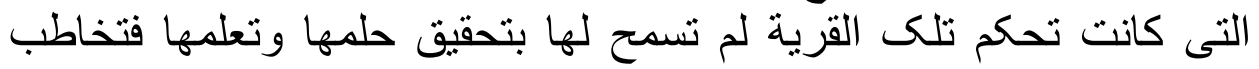

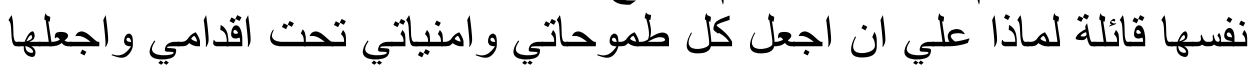

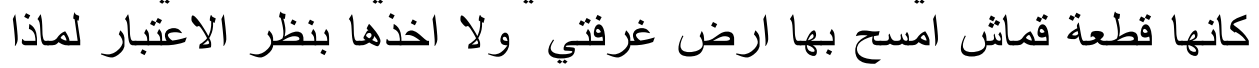




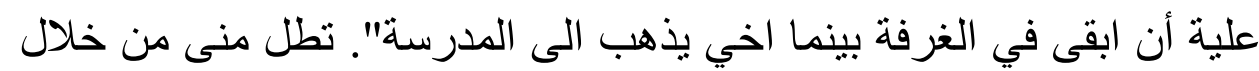

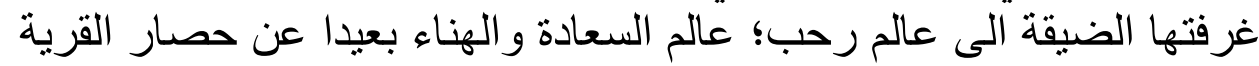

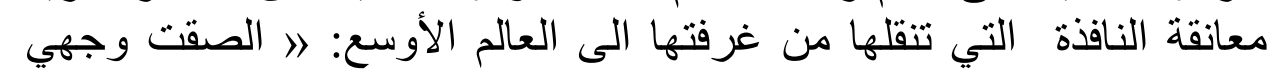

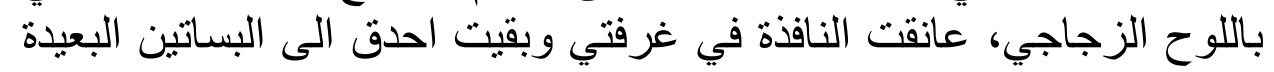

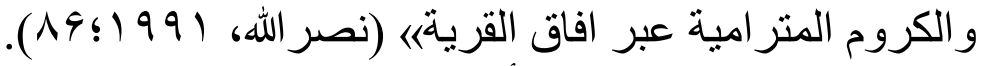

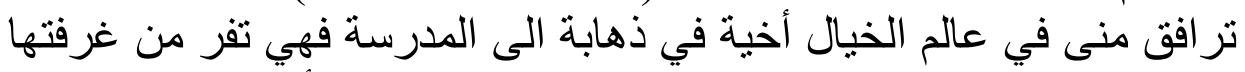

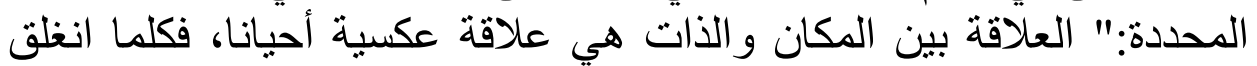

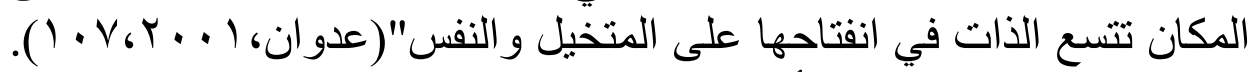

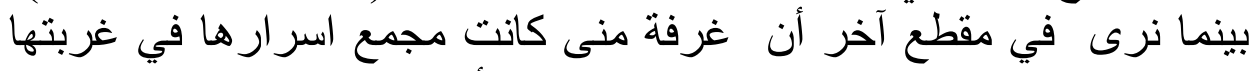

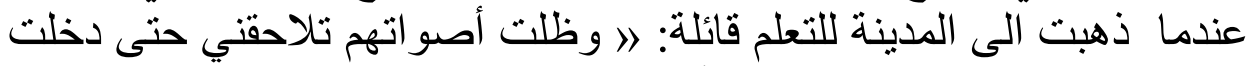

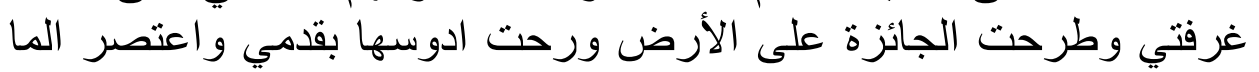

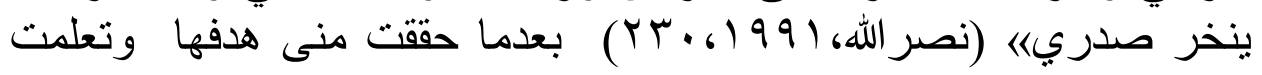

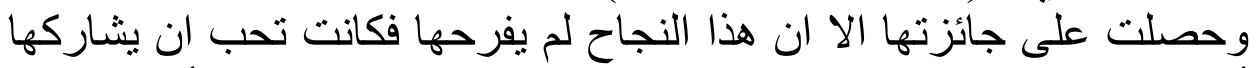

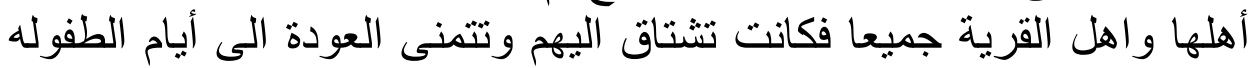

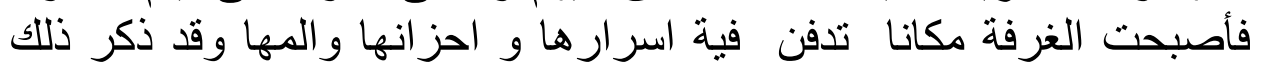

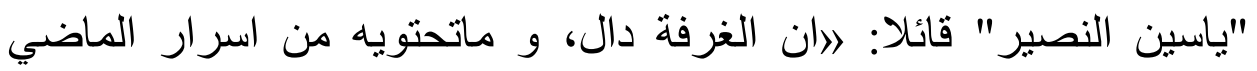

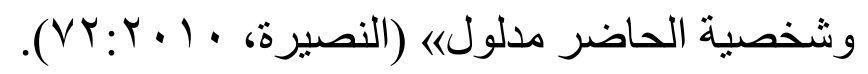

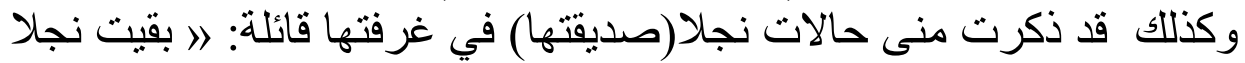

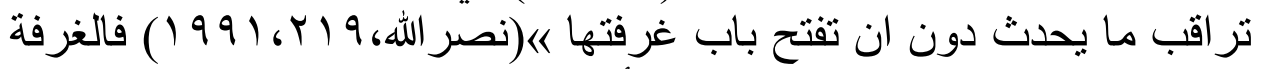

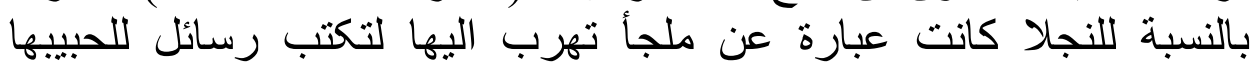

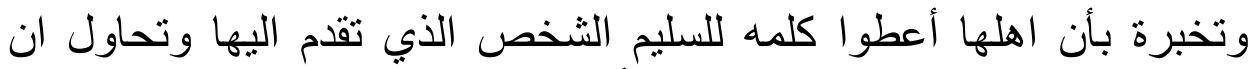
تجلبوة اليها وكانت الغرفة هذة مكان الأمان لها ولر احتها وذكرياتها مع حبيبها

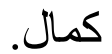
فالغرفة وحضور ها فى القصة عن رؤية الثخصيات المؤنثة تدل على الفجوة العميقة بين الأجيال المختلفة في القرية.

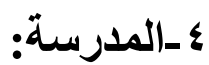

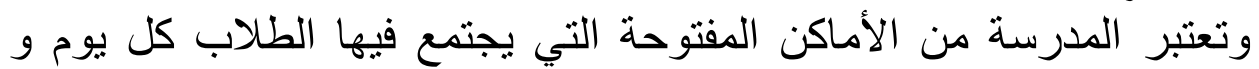

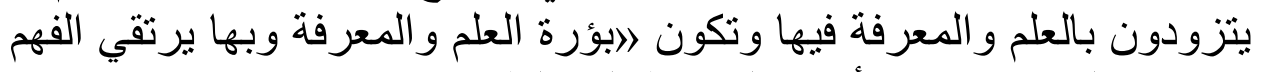

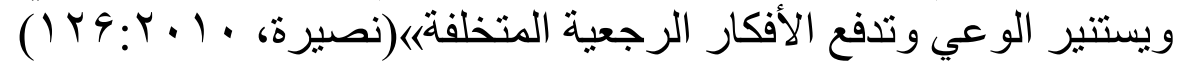


وتنثير منى إلى المدرسة قائلة:الاتذكرت ان أخي يحزم حقائبة استعدادا

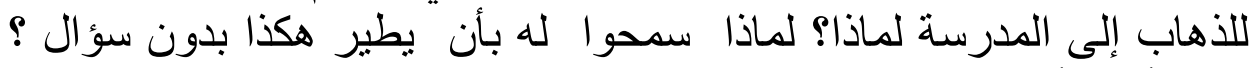

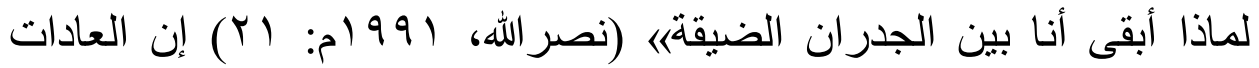

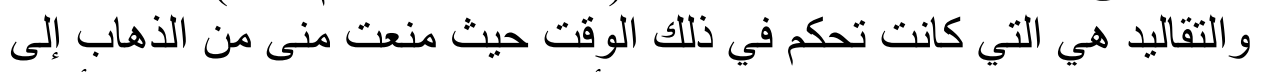

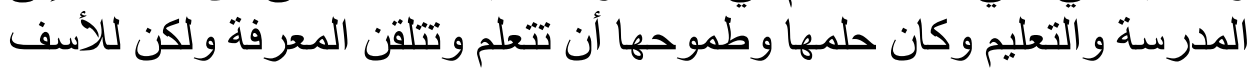

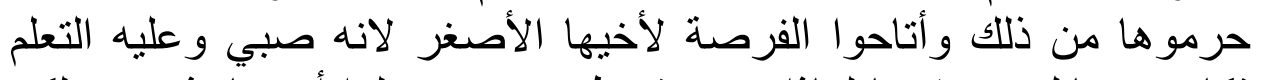

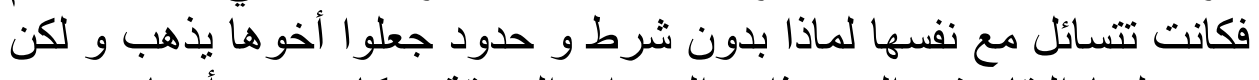

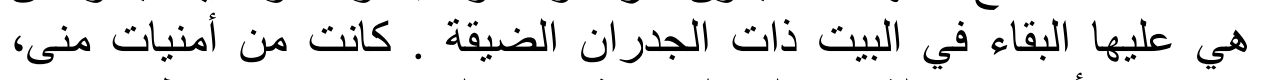

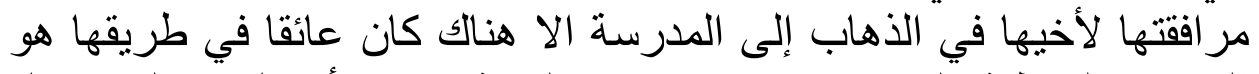

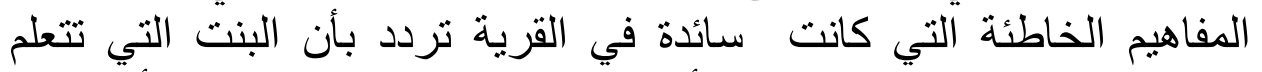

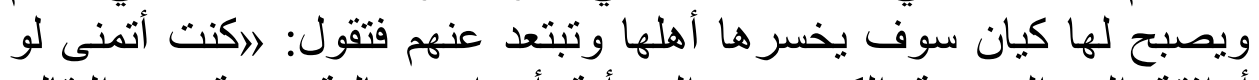

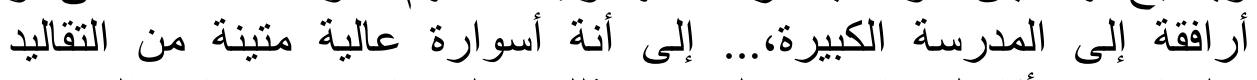

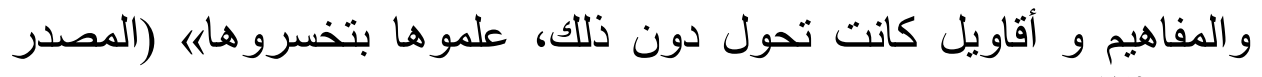

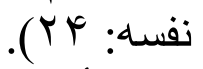

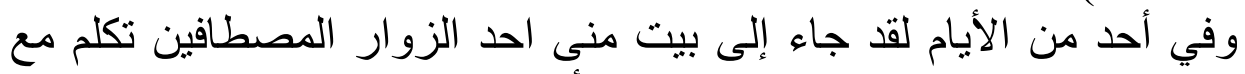

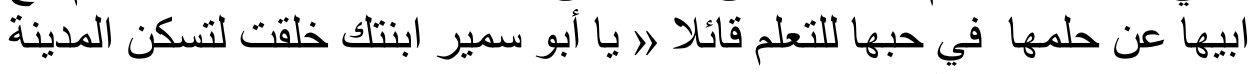

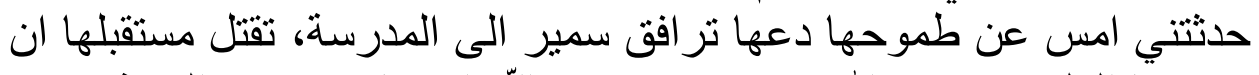

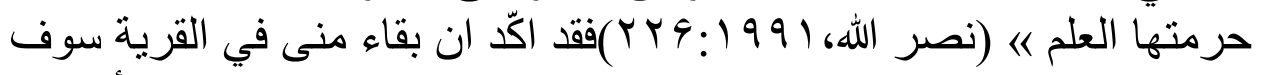

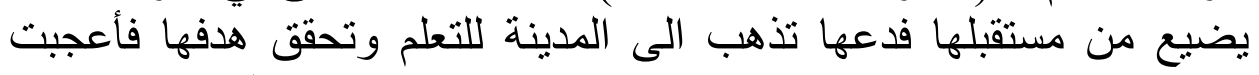

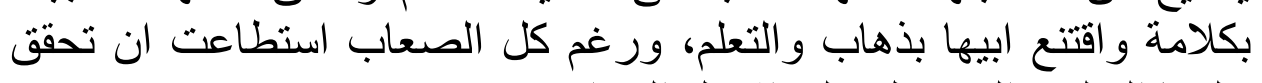

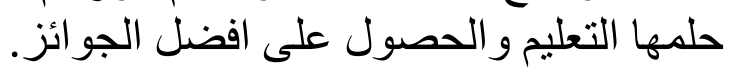

الهجرة من المظاهر القديمة التي اهتم بها الأدباء منذ القدم وهي ظاهرة

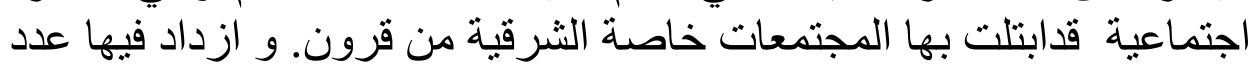

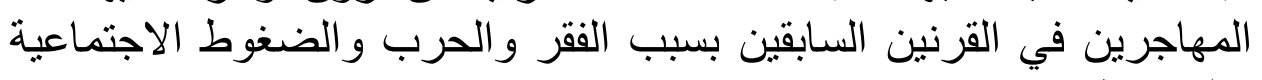
و السياسية. شاعت الهجرة في البلاد العربية منها "لبنان" في قرن العشرين اثر هجمة

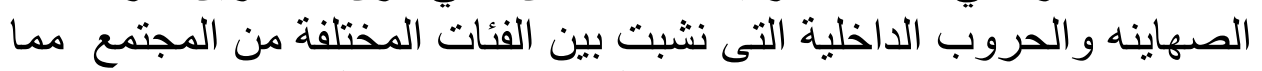
ادى الى انهام البنى التحتية وهجرة الأبناء الى البلاد الأجنبية خاصة آلئية آمريكا وكندا. 
تأثرت اميلي نصر الله في آثار ها بظاهرة الهجرة حتى سماها النقاد "كاتبة

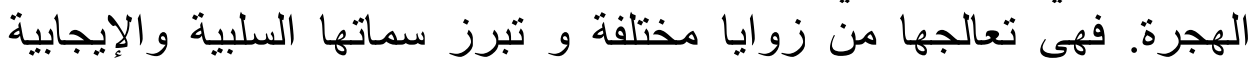
وذلكى من خلال الحوارات التى تجرى على على ألسن الثخصيات و وأعمالهم خلال

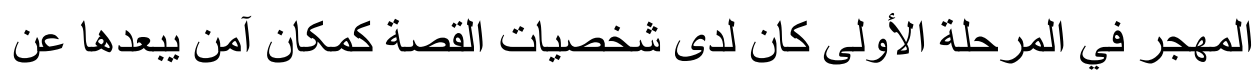

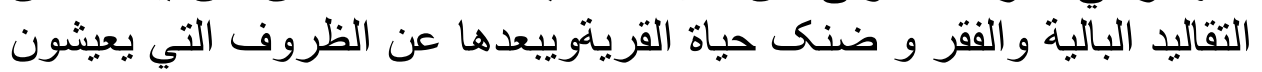

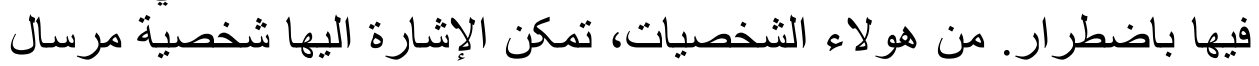

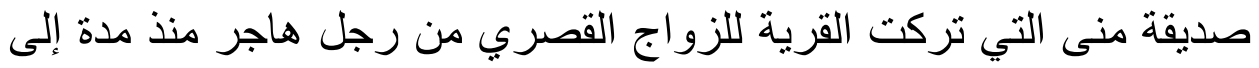

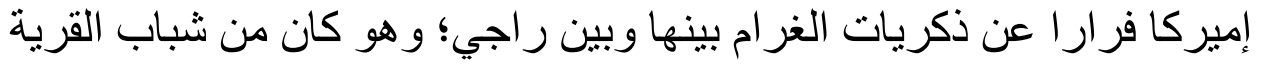

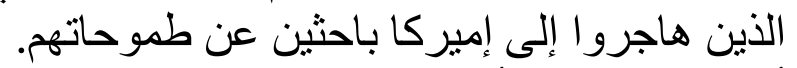

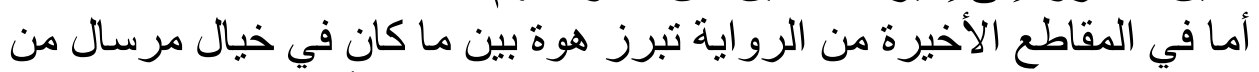

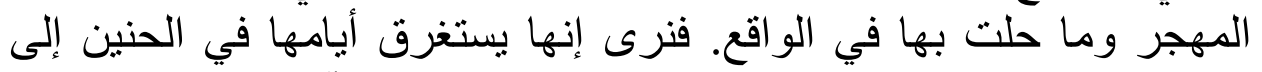

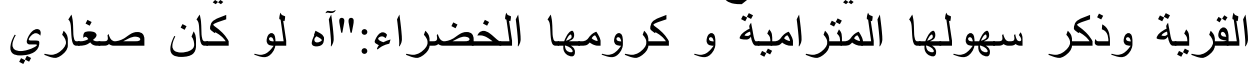

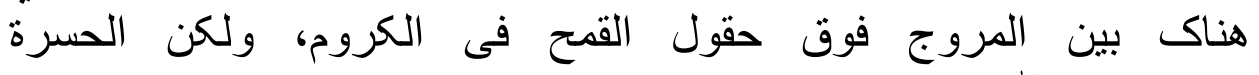

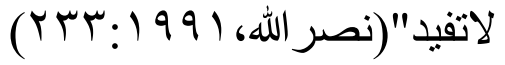

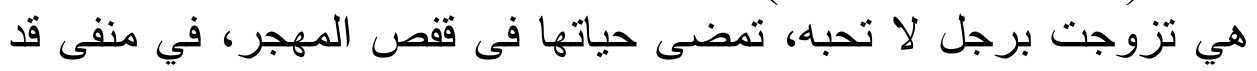

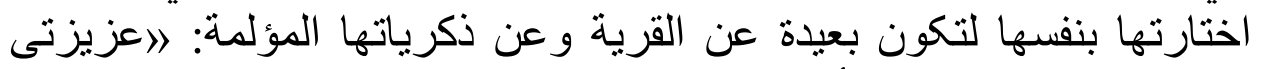

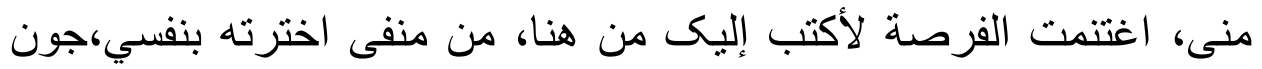

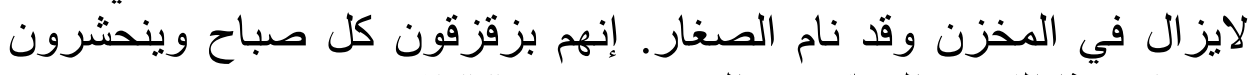

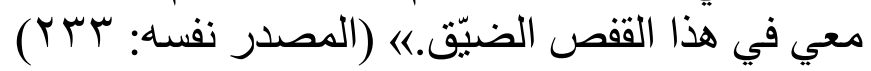

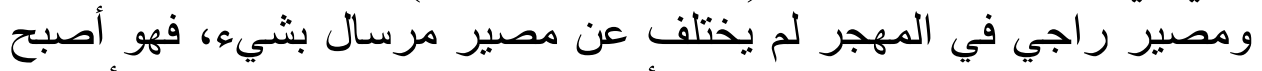

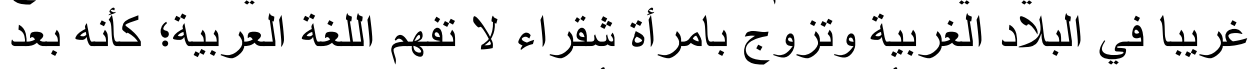

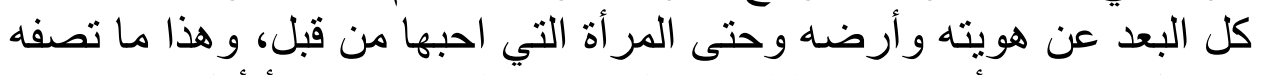

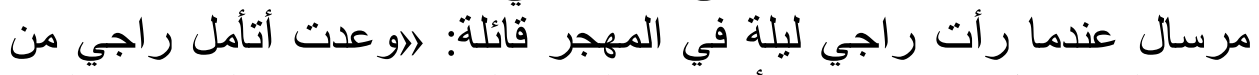

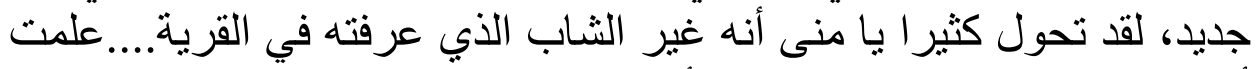

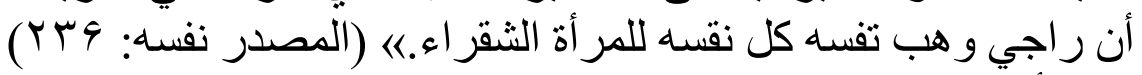

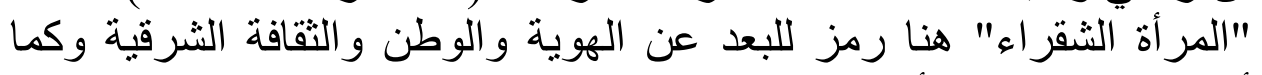

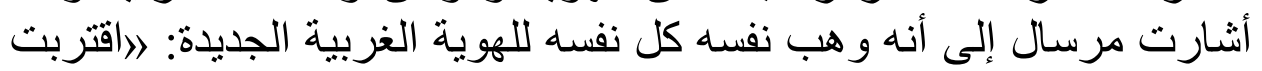

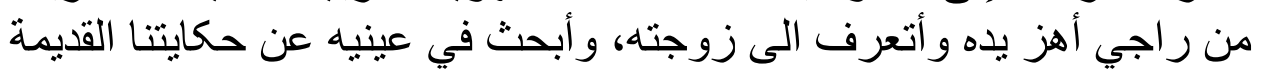

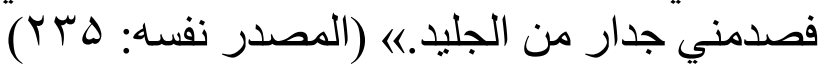


و المهجر في هذه الرواية محل تحقق أحلام الثباب وطموحاتهم في الحياة:

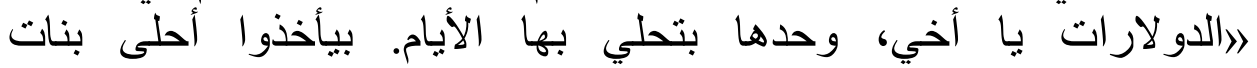

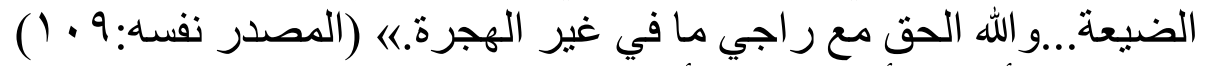

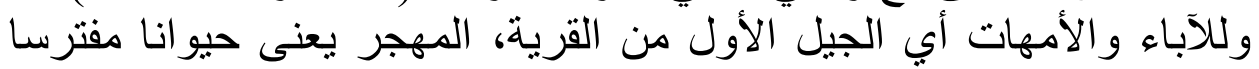

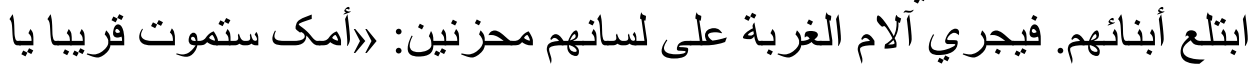

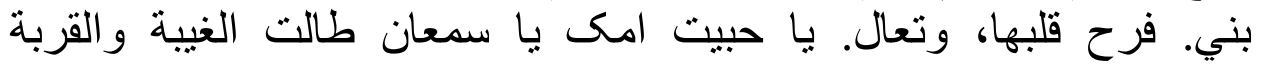

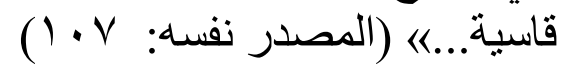

القد توصل هذائج: البحث إلى الى نتائج عديدة ومن أهمها:

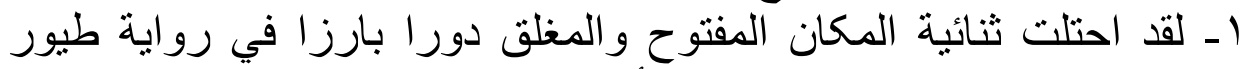

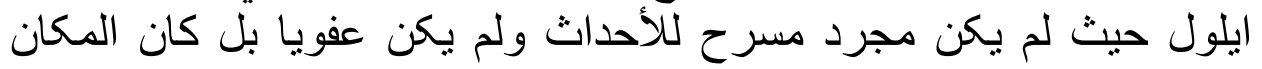

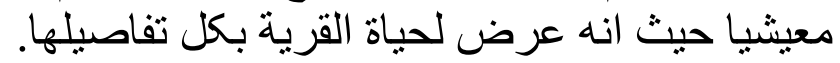

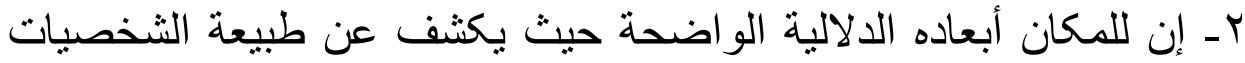

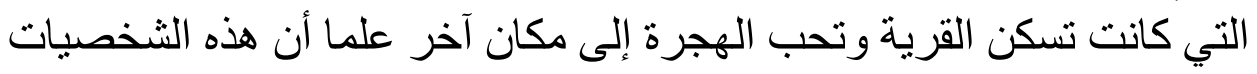

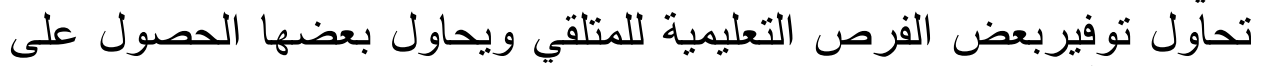
المال من أجل العيش وتبعد الثخصيات المذكورة عن العادات و التقاليد القديمة علية

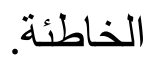

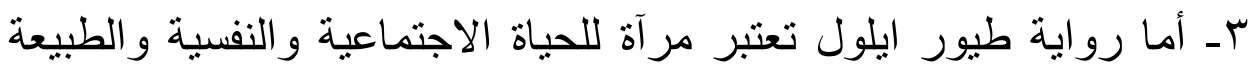

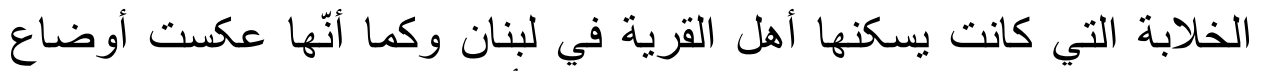

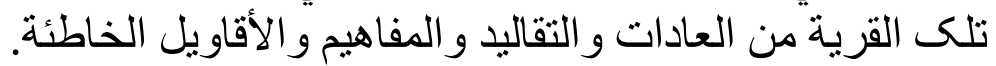

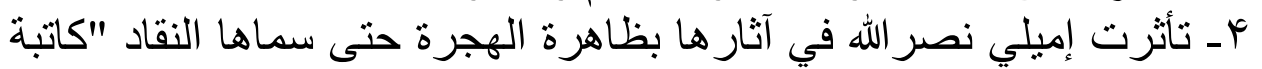

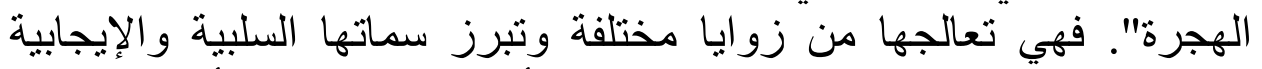

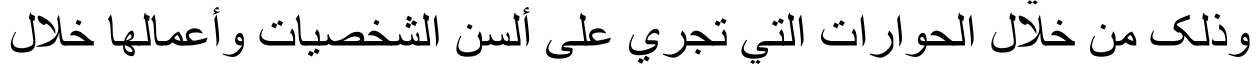

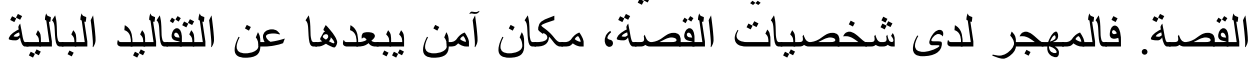
و الفقر وضنك حياة القرية وبالنسبة للجيل الأول يعد مكانا يثير الحرمان التيان

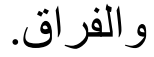

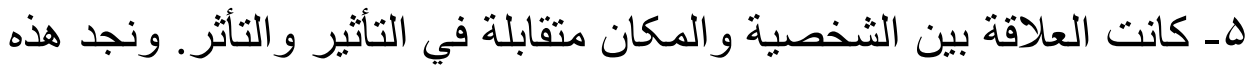

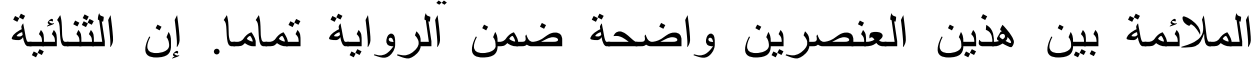

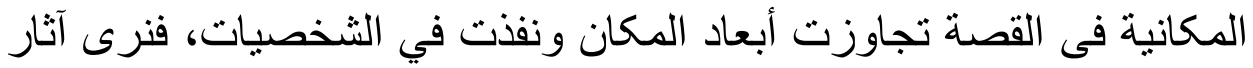

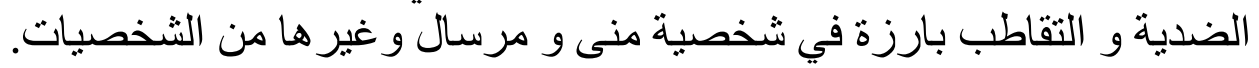




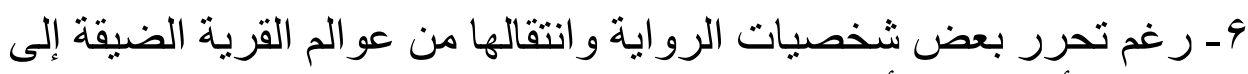

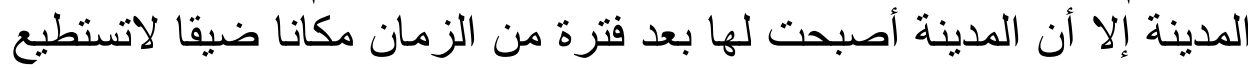

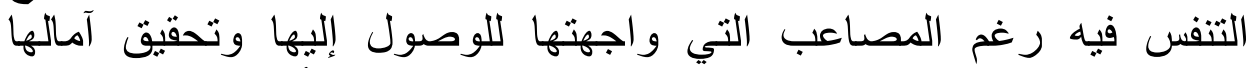

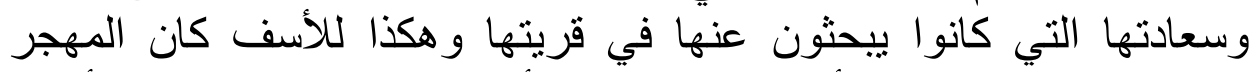

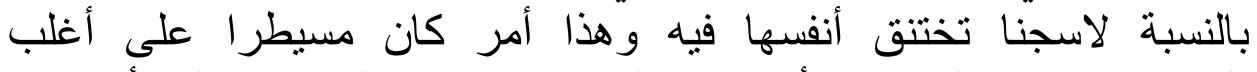

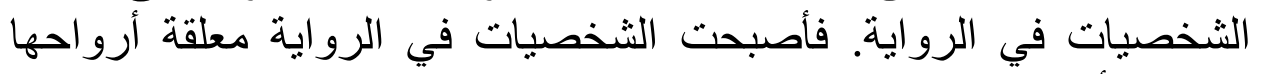
بالقرية و أجسادها بالمدينة. المصادر والمراجع والجماديم

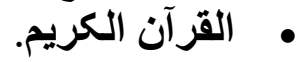

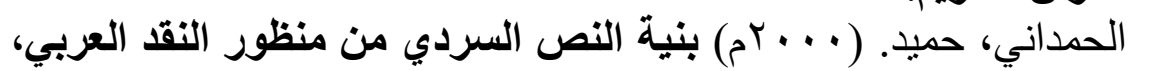

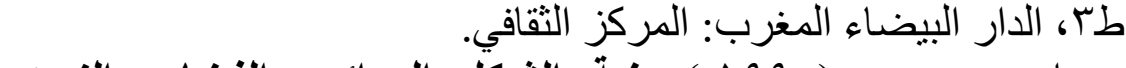

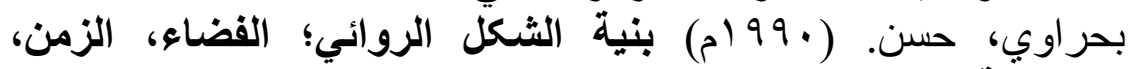

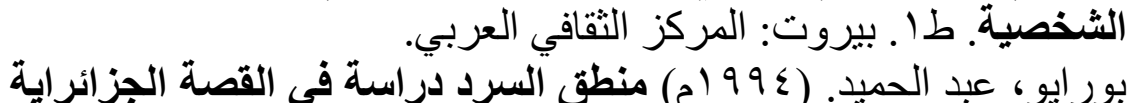

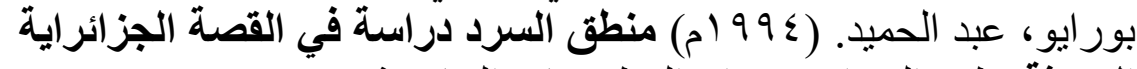
الحديثة. طا ـ الجز ائر : ديوان المطبو عات الجنات الجامعية.

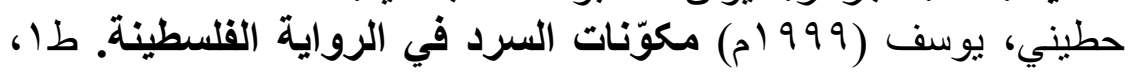

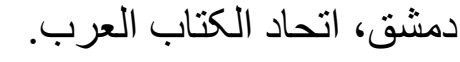

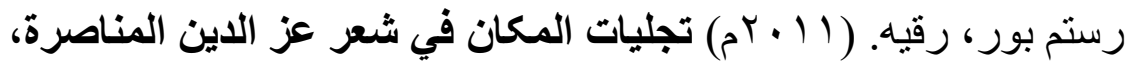

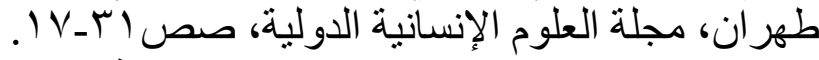

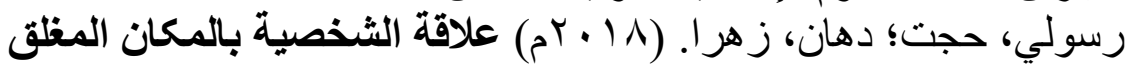

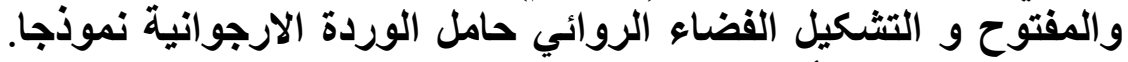

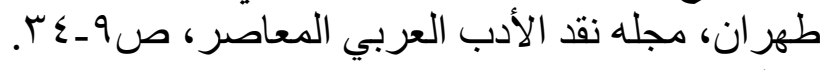

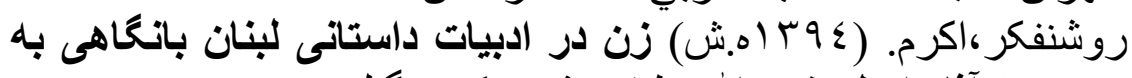

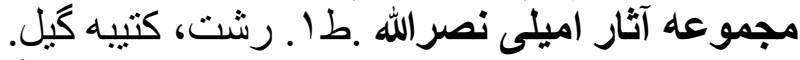

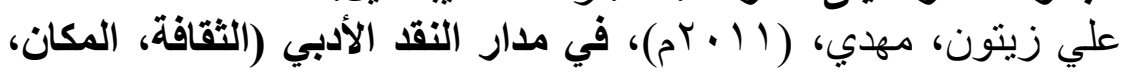
القص)، بيروت: دار الفار (ابي.

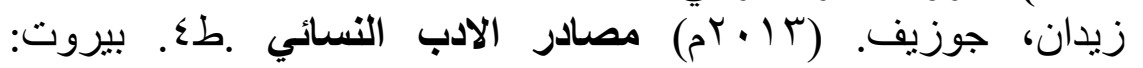
المؤسسة العربية للار اسات و والنشر.

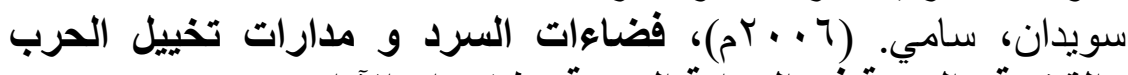

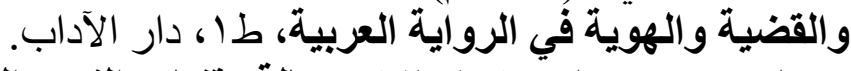

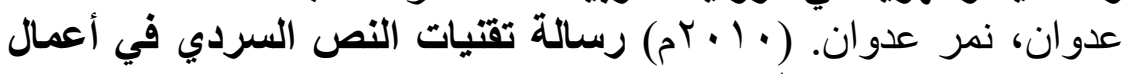

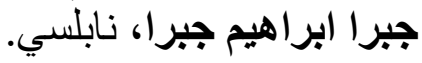


الـتقـاطب الـمكـانـي في رو ايـة طيـور أيسلـول لإميـلي نسرالله 19

1

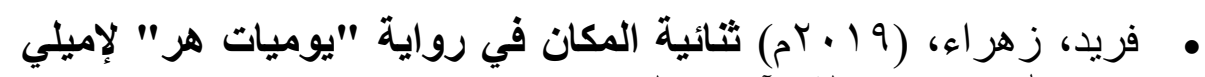

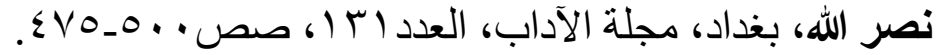

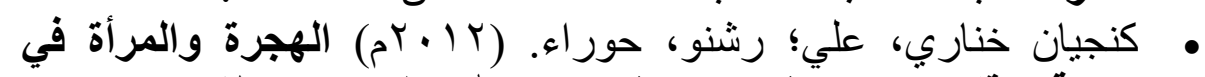

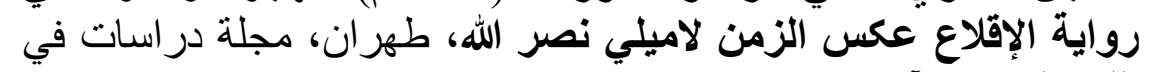

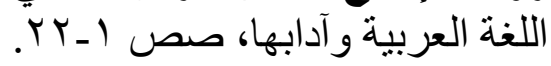

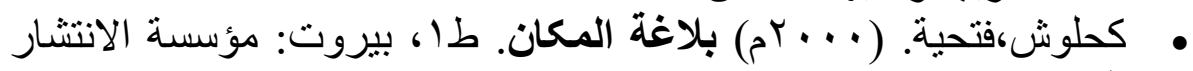
العربي.

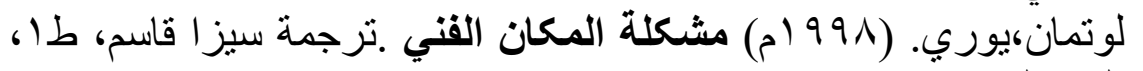

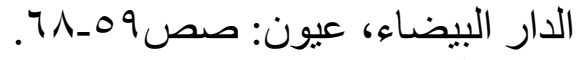

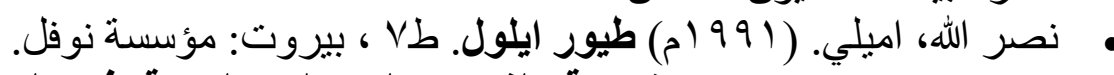

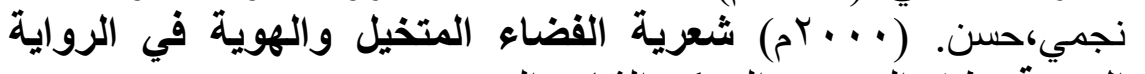

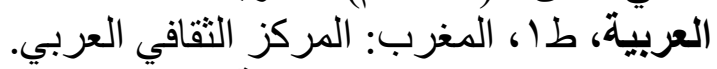

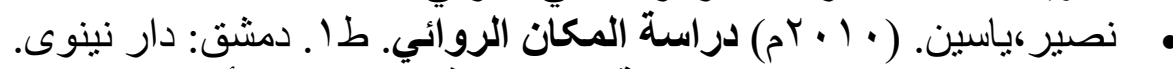

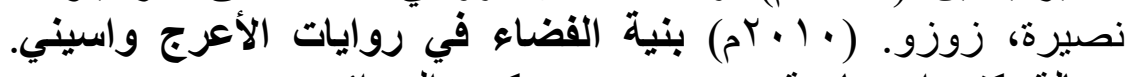

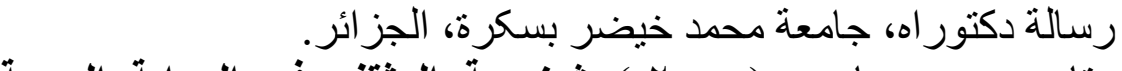

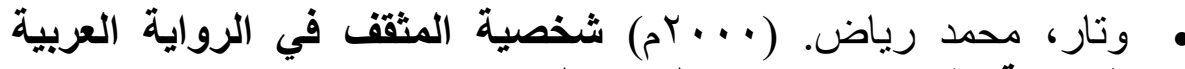

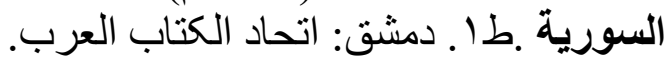




\section{19}

\section{References}

- The Holy Quran

- Al-Hamdani, Hamid, 2000 A.D. Built the narrative text from the perspective of Arab criticism. 3- Dar Al-Bayda, Morocco: The Cultural Center

- Bahrawi, Hassan. 1990 AD The Structure of the Narrative Form SpaceTime-Personal. 1. Beirut: The Arab Cultural Center

- Burayo, Abdel Hamid, 1994 A.D. The logic of narration, a study of the modern Algerian story. 1. Algeria: University Press Office

- Hattini, Yusef 1999 A.D. The components of narration in the Palestinian novel, i 1, Damascus, Arab Writers Union

- Rustum Pour, Raqiqa, 2011. The Manifestations of Place in the Poetry of Izz ad-Din al-Manasrah, pp. 17-31, Tehran, The International Journal of Human Sciences.

- Rasuli-Paint, Hajjat-Zahra, 2018 AD: The relationship of the character to the closed and open space and formation The narrative space The Purple Rose bearer as a model. 9-34, Tehran, Shahid Beheshti University

- Roshanfakar, Akram. 1394 Sh. Zan Dar Adabiyat Dastani, Lebanon Banahi, by the collection of the relics of Amy Nasrallah. I. Rasht.

- Ali Zaitoun, Mahdi, (2011), in the orbit of literary criticism (culture place - storytelling), Beirut: Dar Al-Farabi

- Zaidan, Joseph, 2013, Sources of Women's Literature, ed. 4. Beirut: The Arab Foundation for Studies and Publishing.

- Suwaidan, Sami, 2006 A.D. Spaces of Narration and Orbits of Imagination, War, Issue, and Identity in the Arabic Novel.

- Adwan, Nimr Adwan. 2010 AD. Risalah, Narrative Text Techniques in the Works of Jabra Ibrahim Jabra. Nabulsi.

- Farid, Zahra. 2019. Two-place in the novel "The Days of Herr" by Emily Nasrallah, pp. 500-475 Baghdad, Al-Adab Magazine, Issue 131.

- Ganjian Khanari-Rashnu, Ali-Hawra. 2012. Emigration and Women in the novel The Take Off, Reverse the Time, by Emily Nasrallah, pp. 122. Tehran: Journal of Studies in Arabic Language and Literature.

- Kahloush, Fathia 2000 AD, Al-Balaghah Al-Makan, i-1, Beirut: The Arab Expansion Foundation

- Lutman, Uri 1998. The Problem of the Artistic Place, translated by Siza Kassem, T1, Morocco: Dar Al-Bayda

- Nasrallah, Emily. 1991 AD, the birds of September. 7th i. Beirut: Nofal Foundation 


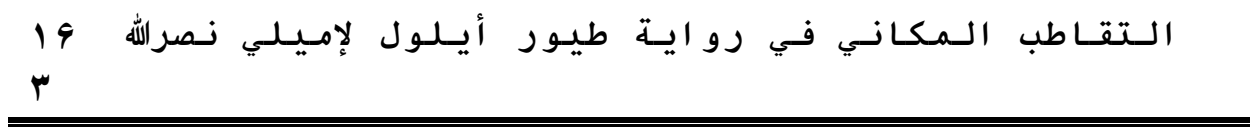

- Astral, Hassan. 2000 AD. Poetics of Imagination and Identity Space in the Arabic Novel. I. Morocco: the cultural center

- Naseer, Yassin. 2010. The Study of the Fictional Place. T1. Damascus: Dar Ninawi.

- Nusayra, Zuzzo 2010. Space structure in the novels of Al-Araj and Wassini. PhD thesis. University of Mohamed Khaider Biskra

- Wattar, Muhammad Riyad, 2000 AD, the personality of the intellectual in the Syrian Arabic novel, I . Damascus: Union of Arabs. 


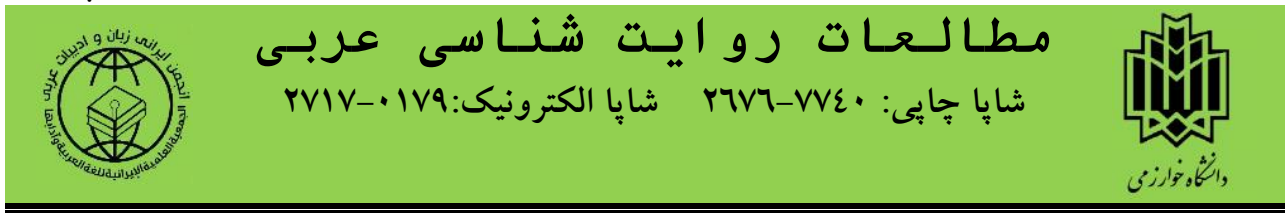

\section{دوتانكَى مكانى در رمان "طيور ايلول) اميلى نصر الله}

r.rostampour@alzahra.ac.ir

رايانامه:

رقيه رستمهيور ملكى

دانشيار كروه زبان و ادبيات عربى دانشعاه الزهرا، تهران، ايران.

z.farid@alzahra.ac.ir رايانامه:

زهرا فريد

استاديار كروه زبان و ادبيات عربى دانشعاه الزهرا، تهران، ايران. (نويسنده مسئول) z.alhosseini@student.alzahra.ac.ir رايانامه:

زهرا حسينى

$$
\text { دانشجوى كارشناسى ارشد زبان و ادبيات عربى دانشعاه الزهرا، تهران، ايران. }
$$

جكيده

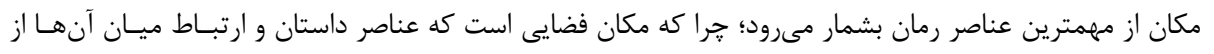

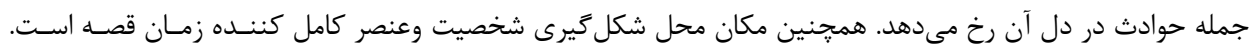

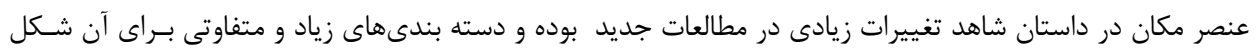

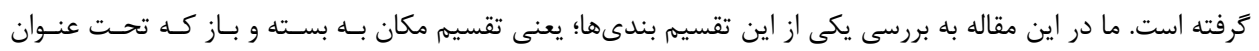

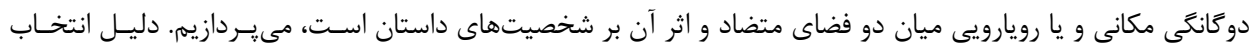

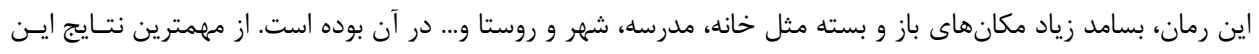

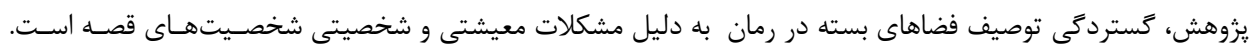

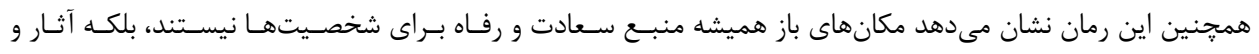

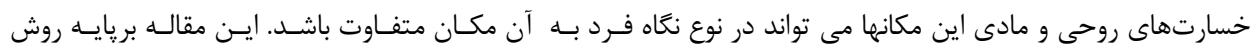
توصيفى - تحليلى است.

كليد وازهها: رمان، دوكانتى مكانى، شخصيت، اميلى نصرالله، طيور ايلول، روايت شناسى عربى.

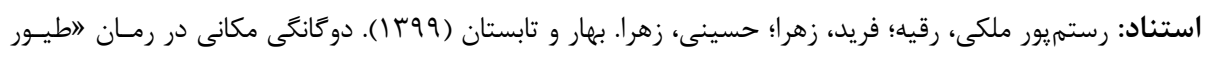

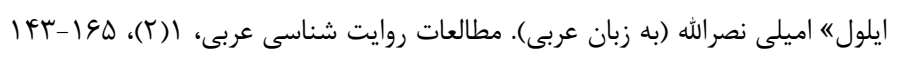

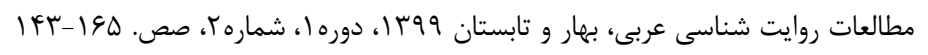

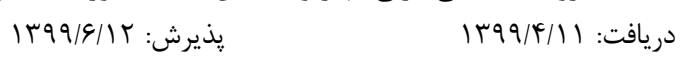

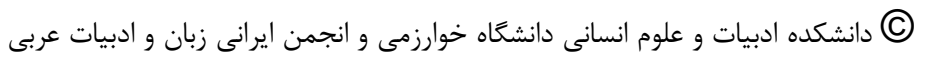

